\title{
Protection from Acoustic Trauma Is Not a Primary Function of the Medial Olivocochlear Efferent System
}

\author{
E. Christopher KIrk, ${ }^{1}$ ANd DAVId W. SMith ${ }^{2}$ \\ ${ }^{1}$ Department of Biological Anthropology and Anatomy, Duke University Medical Center, Durham, NC 27710, USA \\ ${ }^{2}$ Hearing Research Laboratories, Division of Otolaryngology-Head and Neck Surgery, Duke University Medical Center, \\ Durham, NC 27710, USA
}

Received: 2 April 2002; Accepted: 26 March 2003; Online publication: 6 June 2003

\section{ABSTRACT}

The medial olivocochlear (MOC) efferent system is an important component of an active mechanical outer hair cell system in mammals. An extensive neurophysiological literature demonstrates that the MOC system attenuates the response of the cochlea to sound by reducing the gain of the outer hair cell mechanical response to stimulation. Despite a growing understanding of MOC physiology, the biological role of the MOC system in mammalian audition remains uncertain. Some evidence suggests that the MOC system functions in a protective role by acting to reduce receptor damage during intense acoustic exposure. For the MOC system to have evolved as a protective mechanism, however, the inner ears of mammals must be exposed to potentially damaging sources of noise that can elicit MOC-mediated protective effects under natural conditions. In this review, we evaluate the possibility that the MOC system evolved to protect the inner ear from naturally occurring environmental noise. Our survey of nonanthropogenic noise levels shows that while sustained sources of broadband noise are found in nearly all natural acoustic environments, frequency-averaged ambient noise levels in these environments rarely exceed $70 \mathrm{~dB}$ SPL. Similarly, sources reporting ambient noise spectra in natural acoustic environments suggest that noise levels within narrow frequency bands are typically low in intensity $(<40 \mathrm{~dB}$ SPL). Only in rare instances (e.g., during frog choruses) are

Correspondence to: David W. Smith - Box 3550 - Duke University Medical Center • Durham, NC, 27710 • Telephone: (919) 681-6379; fax: (919) 684-5160; email: earsdws@duke.edu ambient noise levels sustained at moderately high intensities ( 70-90 dB SPL). By contrast, all experiments in which an MOC-mediated protective effect was demonstrated used much higher sound intensities to traumatize the cochlea (100-150 dB SPL). This substantial difference between natural ambient noise levels and the experimental conditions necessary to evoke MOC-mediated protection suggests that even the noisiest natural acoustic environments are not sufficiently intense to have selected for the evolution of the MOC system as a protective mechanism. Furthermore, although relatively intense noise environments do exist in nature, they are insufficiently distributed to account for the widespread distribution of the MOC system in mammals. The paucity of highintensity noise and the near ubiquity of low-level noise in natural environments supports the hypothesis that the MOC system evolved as a mechanism for "unmasking" biologically significant acoustic stimuli by reducing the response of the cochlea to simultaneous low-level noise. This suggested role enjoys widespread experimental support.

Keywords: cochlea, efferent protection, noiseinduced hearing loss

\section{INTRODUCTION}

Cochlear outer hair cells are mechanically active and provide the exquisite sensitivity and frequency selectivity characteristic of the mammalian auditory system. Because outer hair cell function is modulated by 
descending, medial olivocochlear (MOC) efferent neurons, the MOC system is an important component of a mechanically active cochlea. While the specific physiological and psychophysical effects of MOC activity on audition are well documented (e.g., Brown et al. 1983; Winslow and Sachs 1987; Kawase et al. 1993; May and McQuone 1995; Liberman et al. 1996; Lima da Costa et al. 1997; Smith 1998), the actual biological role of the MOC system is less clear (cf. Guinan 1996). In this regard, the current neurophysiological data are inconclusive, suggesting that the MOC system could play two very different roles in mammalian hearing.

First, a number of investigators have provided evidence that the MOC system suppresses the response of the cochlea to concurrent noise and, in so doing, helps to "unmask" transient acoustic stimuli (Nieder and Nieder 1970; Winslow and Sachs 1987, 1988; Dolan and Nuttall 1988; Kawase and Liberman 1993; Kawase et al. 1993; Liberman and Guinan 1998). These sources support the hypothesis that the MOC system evolved as a means of improving the signal-tonoise ratio and the dynamic range of the peripheral auditory system.

Second, Rajan (1988a,b, 1995a,b, 1996, 2000, 2001a), Rajan and Johnstone (1983, 1988a,b,c), and others (Handrock and Zeisberg 1982; Liberman and Gao 1995; Reiter and Liberman 1995; Zheng et al. 1997) have shown that the presence and extent of threshold shifts following intense, high-frequency sound exposure are increased after deactivation of the MOC system, or are decreased when the MOC system is stimulated with either electrical stimulation of the olivocochlear tracts or acoustic stimulation of the contralateral ear. These results support the hypothesis that the MOC system evolved as a protective mechanism that acts to reduce receptor damage during intense noise exposure. By contrast, several studies using similar experimental designs have shown no evidence for MOC-based protective effects (Hildesheimer et al. 1990; Liberman 1991). As is shown later in this analysis, the stimulus conditions that failed to demonstrate efferent protection in some studies overlap in both frequency and intensity the stimuli that are reported to evoke efferent protection in other similar experiments, highlighting the variability of the protective effect (cf. Guinan 1996).

In this review we evaluate the hypothesis that the MOC system evolved to protect the inner ear from naturally occurring environmental noise (the "protection hypothesis"). The reason for this test, as Guinan (1996) has pointed out, is that it is currently unknown whether or not potentially damaging environmental noise was sufficiently common to have influenced the evolution of the MOC system. We first survey the available literature that describes the characteristics of ambient noise in different natural acoustic environments. We then review published reports describing the stimulus parameters necessary to demonstrate a role for the MOC efferent system in protecting the cochlea from noise-induced trauma. By comparing these two sources of data, we are able to determine whether environmental noise that is known to occur under natural conditions may be sufficiently intense to elicit the protective effects of the MOC system. If such protective effects are not induced by naturally occurring acoustic stimuli, it is unlikely that the MOC system could have evolved to protect the inner ear from acoustic trauma.

\section{Distribution of the MOC system among mammals}

The auditory end organs of all tetrapods (including mammals) receive an efferent innervation (Roberts and Meredith 1992; Fritzsch 1992, 1997). However, it is currently unknown whether monotremes, which lack some features of the inner ear shared by marsupial and placental mammals (Ladhams and Pickles 1996), possess an MOC system. All species that have been definitively shown to possess an MOC system are included within four orders of placental mammals (Primates, Chiroptera, Carnivora, Rodentia) and two orders of marsupials (Dasyuromorphia and Didelphimorphia; Table 1). If one assumes that MOC systems in these orders are inherited from a common ancestor and retained in most descendent taxa, then it is likely that all placental and marsupial orders share MOC efferent innervation of cochlear outer hair cells. The distribution of character states among known taxa thus suggests that the MOC system is a general feature of the mammalian auditory system that must have arisen no later than the time of divergence between marsupial and placental mammals (ca. 173 million years before present; Kumar and Hedges 1998).

Furthermore, among mammals for which the anatomy is known, the majority (21 of 24 species) possess cochlear outer hair cells that receive MOC innervation (Table 1). This broad distribution across six orders and 16 families of mammals is striking; it suggests that the MOC system has been maintained by stabilizing selection in most mammalian groups despite pronounced differences in habitat and ecology. Indeed, the only mammals that are known to lack MOC innervation of outer hair cells are the microchiropteran bats Hipposideros and Rhinolophus (Bruns and Schmieszek 1980; Aschoff and Ostwald 1987; Bishop and Henson 1987, 1988; Ostwald and Aschoff 1988) and the blind mole rat Spalax ehrenbergi (Raphael et al. 1991). Although it is currently not known why these taxa have lost their MOC systems, all three genera demonstrate extreme specialization of the auditory apparatus for high-frequency (Hipposid- 
TABLE 1

Taxa known to possess medial efferent innervation of outer hair cells

\begin{tabular}{|c|c|c|}
\hline Order & Genus & Common name (source) \\
\hline \multirow[t]{2}{*}{ Carnivora } & Felis & Cat (Warr and Guinan 1979; Guinan et al. 1983; Liberman et al. 1990) \\
\hline & Canis & Dog (Weber et al. 1987) \\
\hline \multirow[t]{5}{*}{ Chiroptera } & Pteronotus & Moustached bat (Bishop and Henson 1987, 1988) \\
\hline & Artibeus & Neotropical fruit bat (Aschoff and Ostwald 1987) \\
\hline & Phyllostomus & Spear-nosed bat (Aschoff and Ostwald 1987) \\
\hline & Tadarida & Free-tailed bat (Aschoff and Ostwald 1987) \\
\hline & Rhinopoma & Mouse-tailed bat (Aschoff and Ostwald 1987) \\
\hline Dasyuromorphia & Sminthopsis & Dunnart or Marsupial mouse (Henson and Henson, unpublished data) \\
\hline Didelphimorphia & Didelphis & Opossum (Henson and Henson, unpublished data) \\
\hline \multirow[t]{5}{*}{ Primates } & Homo & Human (Nadol 1983, 1990) \\
\hline & Pan & Chimpanzee (Nadol and Burgess 1990) \\
\hline & Macaca & Macaque monkey (Sato et al. 1997, 1999) \\
\hline & Saimiri & Squirrel monkey (Thompson and Thompson 1986) \\
\hline & Otolemur & Bush baby (Thompson and Thompson 1995) \\
\hline \multirow[t]{7}{*}{ Rodentia } & Mus & Mouse (Campbell and Henson 1988) \\
\hline & Rattus & Rat (Aschoff and Ostwald 1987, 1988; Robertson et al. 1989) \\
\hline & Cavia & Guinea pig (Aschoff and Ostwald 1987, 1988) \\
\hline & Chinchilla & Chinchilla (Azeredo et al. 1999) \\
\hline & Pachyuromys & Fat-tailed gerbil (Aschoff et al. 1988) \\
\hline & Meriones & Mongolian gerbil (Aschoff et al. 1988) \\
\hline & Mesocricetus & Golden hamster (Simmons et al. 1996) \\
\hline
\end{tabular}

eros and Rhinolophus) or low-frequency (Spalax) hearing (Bruns 1976a,b; Bruns and Schmieszek 1980; Bruns et al. 1988; Burda et al. 1989; Dannhof and Bruns 1991; Raphael et al. 1991), and may thus be considered atypical models for general mammalian auditory anatomy and function.

\section{ENVIRONMENTAL EVIDENCE: MEASUREMENTS OF AMBIENT NOISE LEVELS}

Our literature search revealed 23 sources reporting environmental sound levels under natural or seminatural conditions (Table 2). "Natural" acoustic environments are here defined as environments that lack significant anthropogenic (human-generated) sound sources. It is important to bear in mind that this definition does not preclude the possibility that some of the environmental sound levels reported in our survey were influenced by human activity (e.g., through selective clearing of forests or reduction of species densities). For instance, Table 2 includes sources reporting ambient sound pressure levels in a pasture (Brenowitz 1982a) and a botanical garden (Brown and Schwagmeyer 1984). Given the comparative paucity of descriptions of natural environmental noise, however, we feel that a relatively inclusive standard is warranted.

Only publications reporting absolute noise levels relative to a stated reference intensity were considered for this analysis. Most of these sources
(Price 1971; EPA 1972; Rosen and Lemon 1974; Luz and Smith 1976; Waser and Waser 1977; Brenowitz 1982ab; Tuttle and Ryan 1982; Schwartz and Wells 1983; Brenowitz et al. 1984; Ryan and Brenowitz 1985; Odendall et al. 1986; Gerhardt and Klump 1988; Römer et al. 1989; Páez et al. 1993; National Park Service 1995; Aubin and Jouventin 1998; Penna and Solís 1998) present frequency-averaged environmental noise levels in $\mathrm{dB}$ A or dB SPL. Six sources, however, present absolute noise intensity levels in dB SPL within multiple frequency ranges (Saby and Thorpe 1946; Morton 1975; Narins 1982; Brown and Schwagmeyer 1984; Waser and Brown 1986; Reiman and Terhune 1993). Of this latter group, the numeric values for noise levels provided by Morton (1975)Waser and Brown (1986), and Reiman and Terhune (1993), as well as the maximum noise levels reported by Narins (1982) within octave bands centered at $1 \mathrm{kHz}(\sim 79 \mathrm{~dB}$ SPL) and $2 \mathrm{kHz}(\sim 92 \mathrm{~dB}$ SPL), are replotted in Figure 1 . The environmental noise levels shown in Figure 1 thus provide a representative cross-section of the total data set shown in Table 2. The noise levels reported by Reiman and Terhune (1993) represent primarily abiotic noise in a calm, nearshore marine setting. By contrast, Morton (1975) and Waser and Brown (1986) document noise levels in tropical forests and grasslands that are rich in biotic noise generated by birds and insects. Narins' (1982) peak noise levels across a narrower frequency range represent the highest naturally occurring noise measurements in Table 2. 


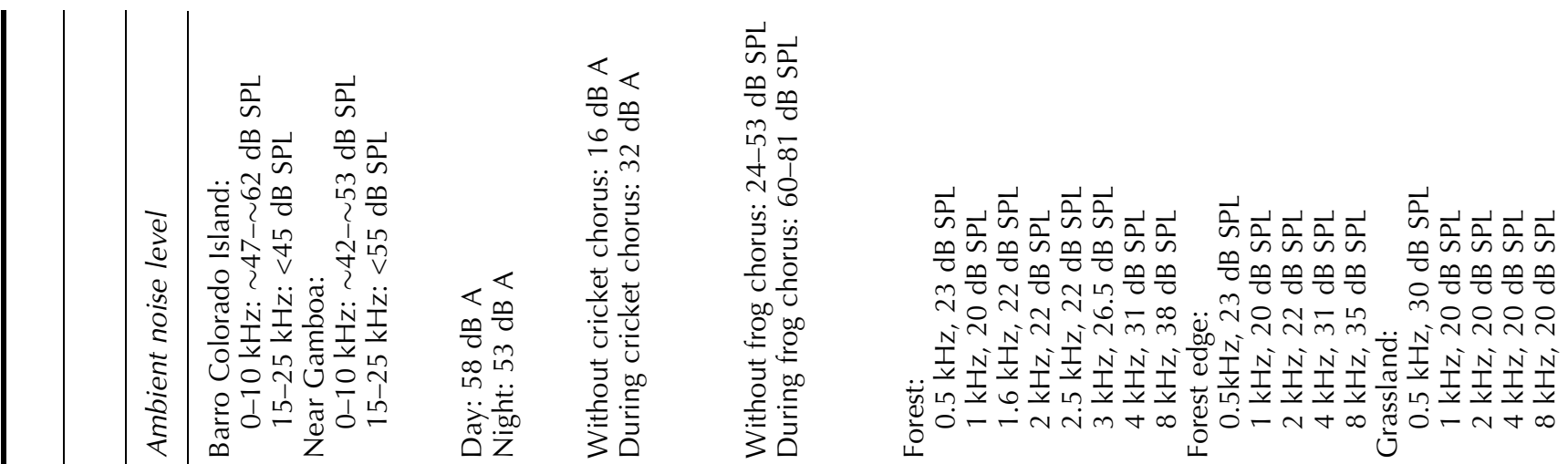

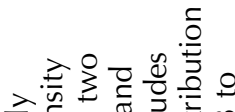

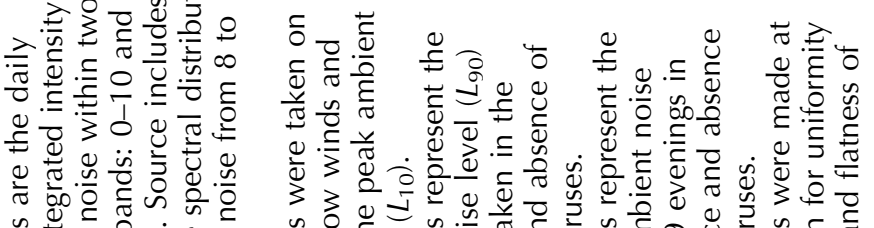

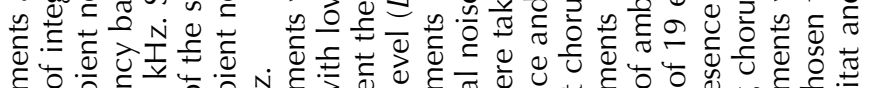

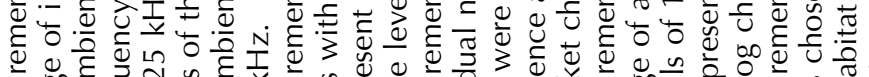

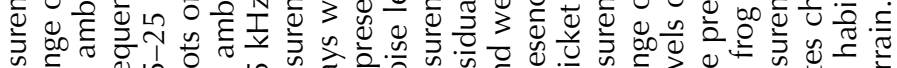

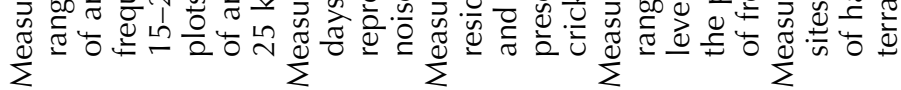
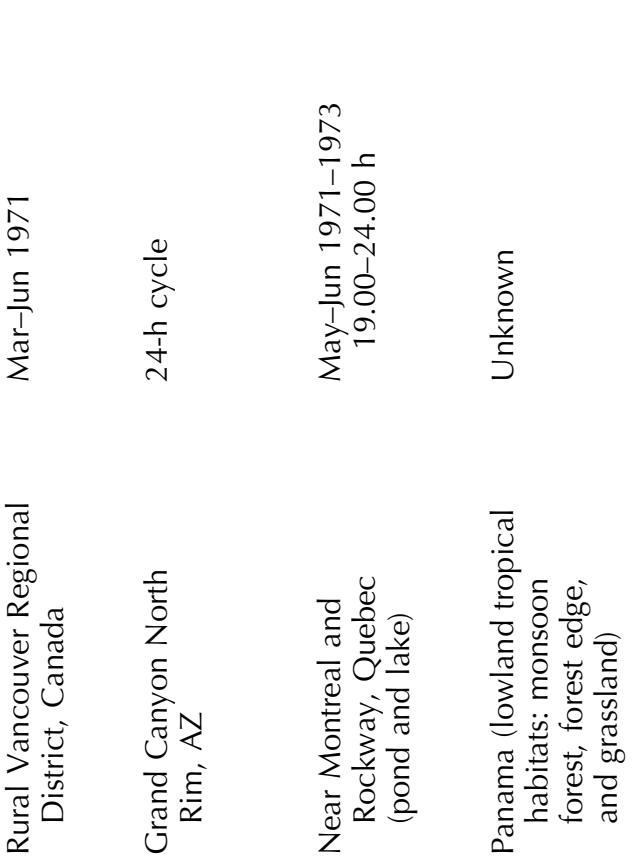

¿

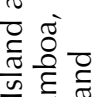

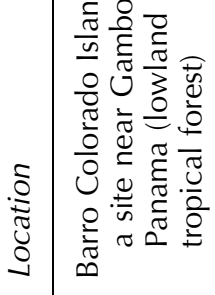

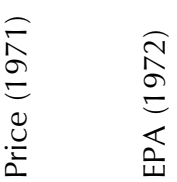

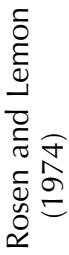

$\widehat{1}$
$\stackrel{2}{\sigma}$
$\stackrel{5}{0}$
$\stackrel{0}{0}$
$\stackrel{0}{2}$ 

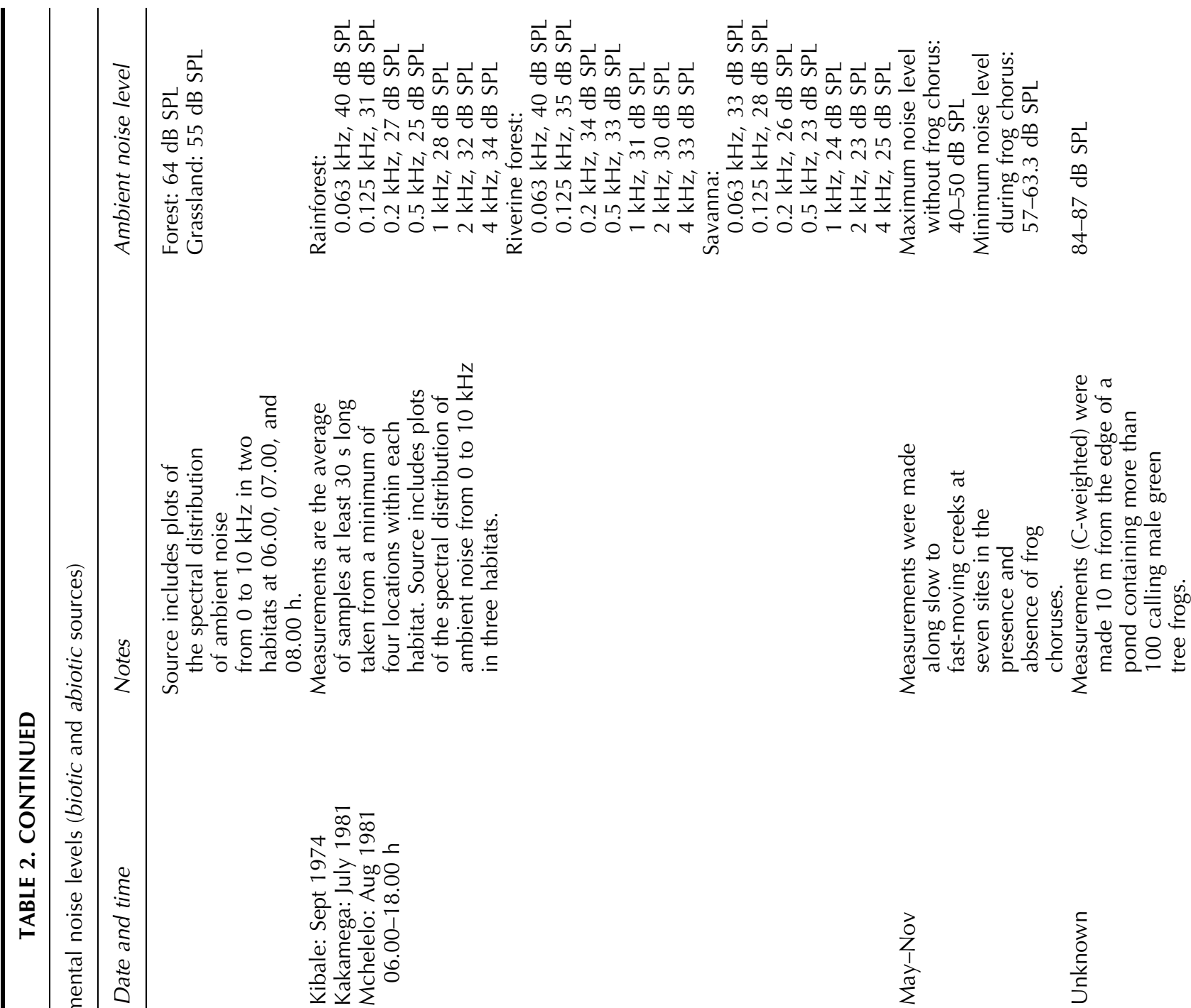

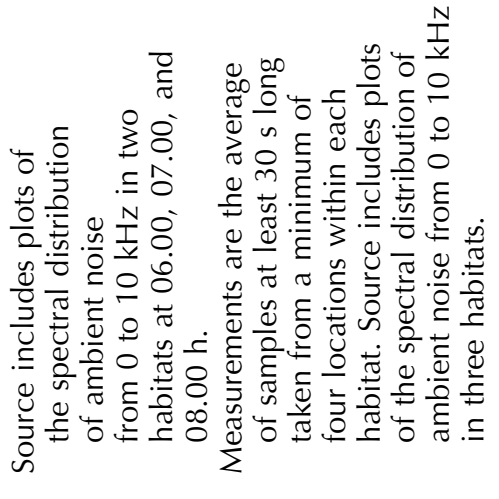
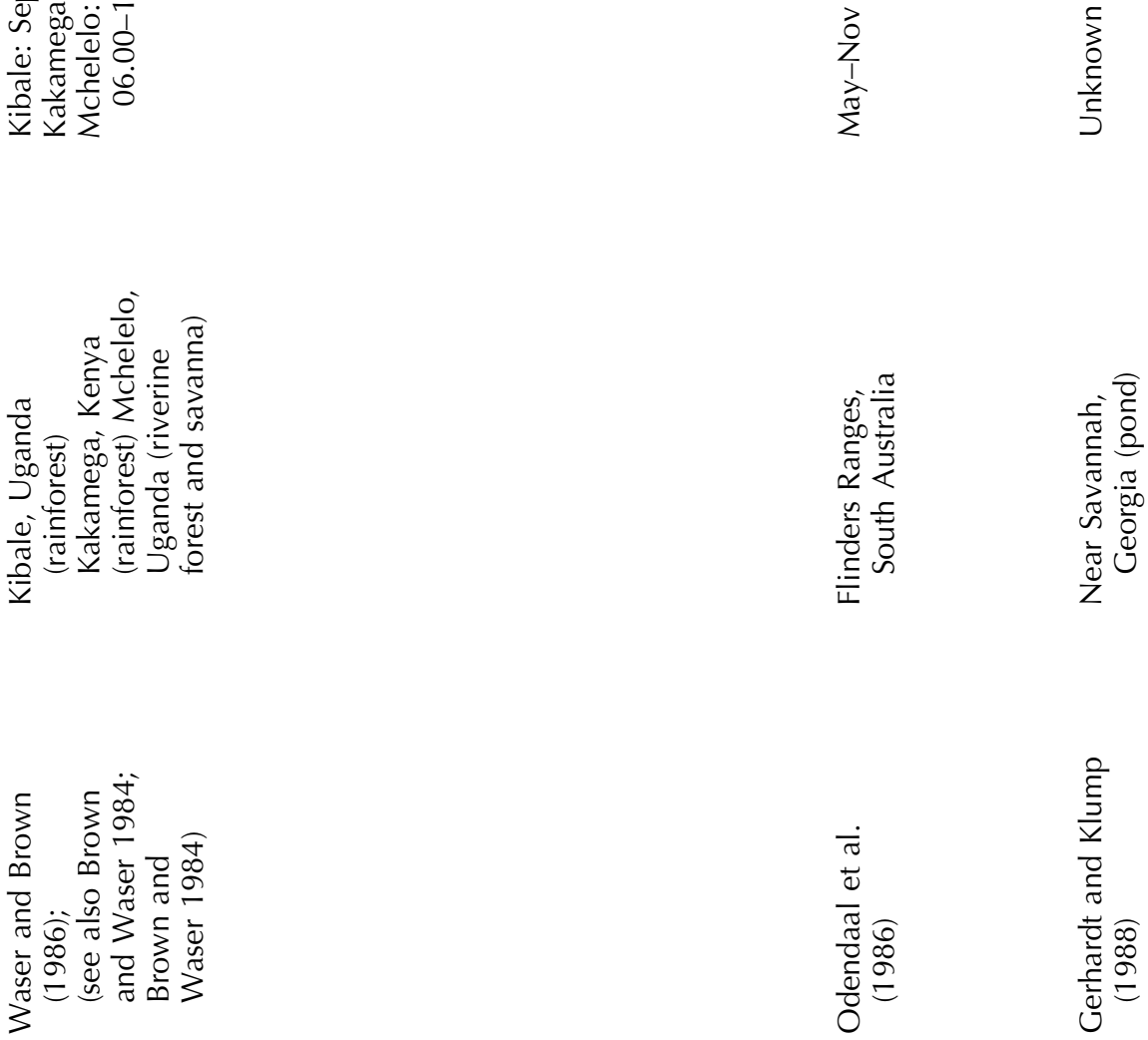


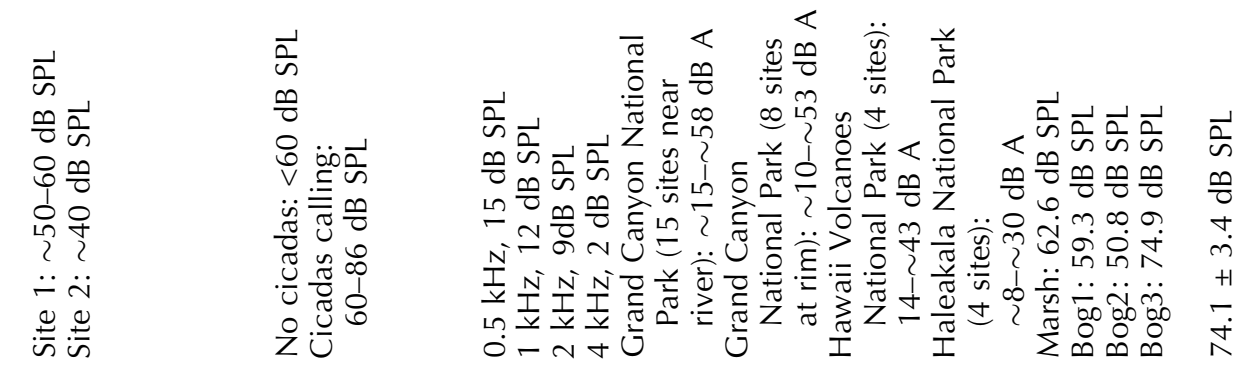

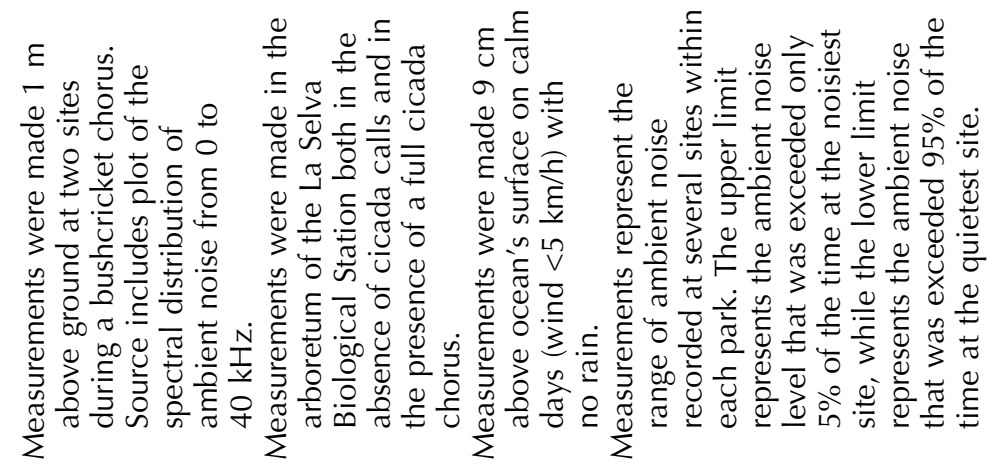

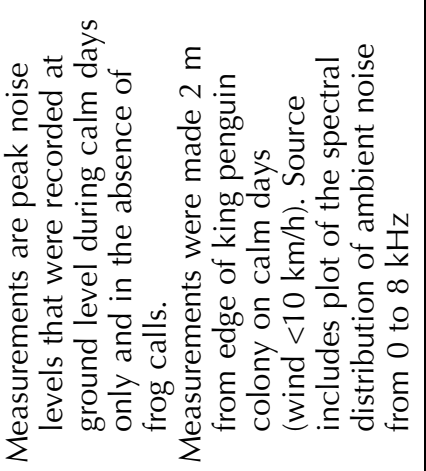

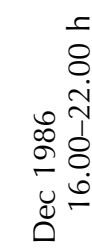

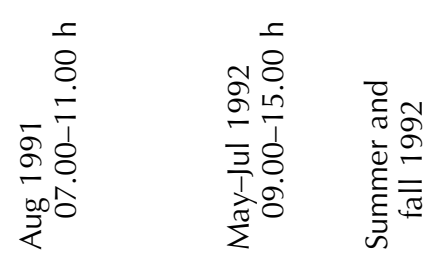

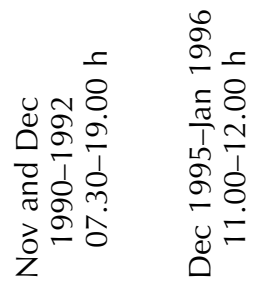

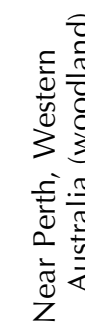
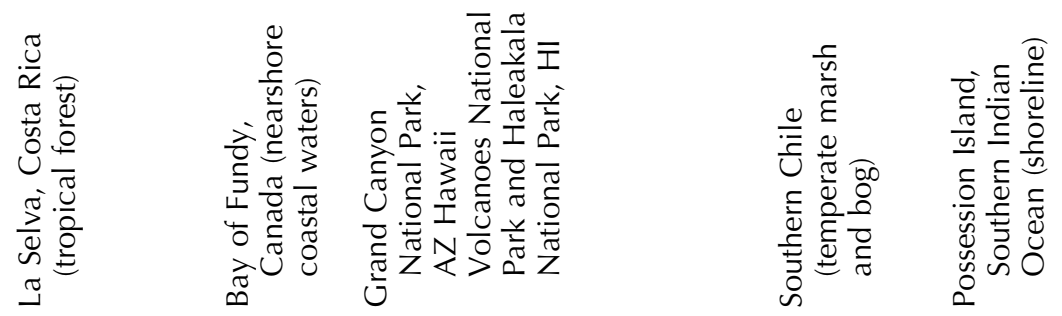

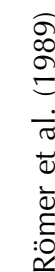
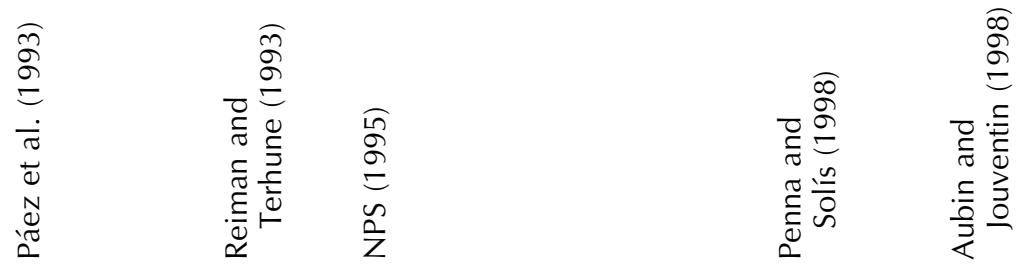


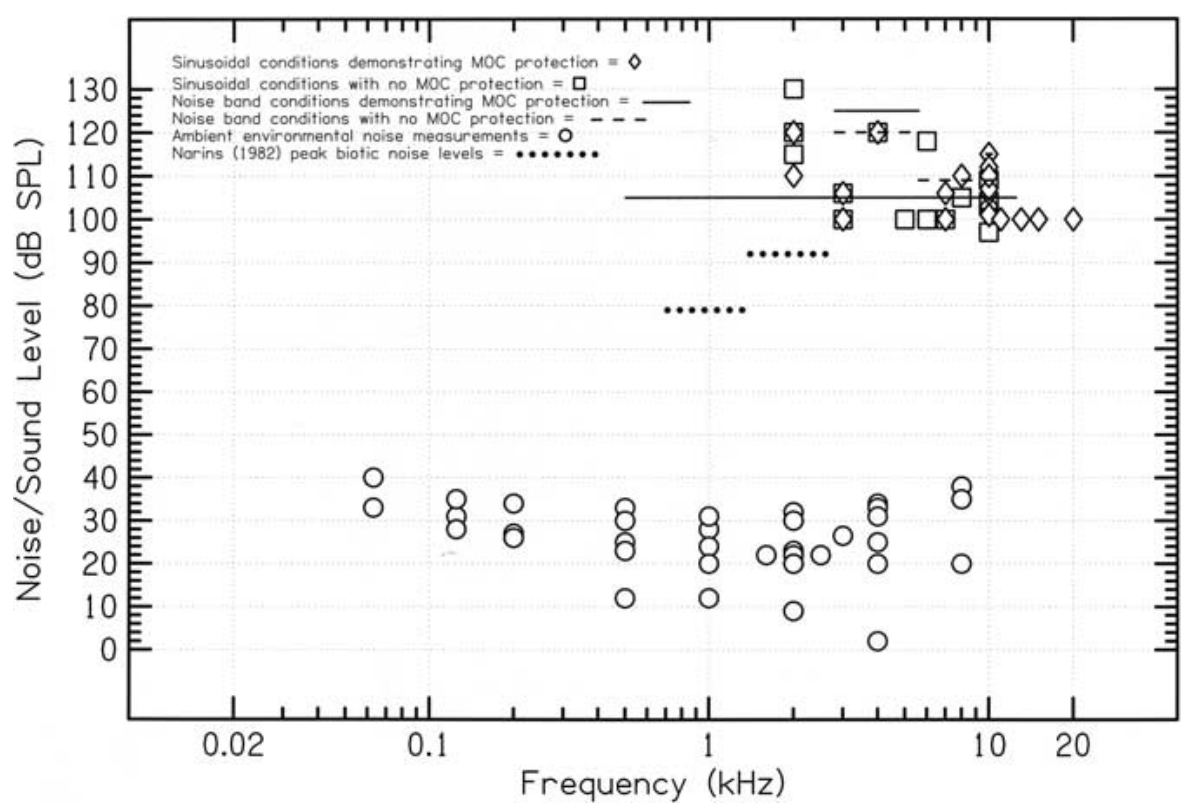

FIG. 1. Diagrammatic plot of naturally occurring noise conditions and stimulus parameters employed in experimental studies of MOCmediated protection from acoustic trauma. Natural environmental noise levels are plotted (open circles) for four studies giving absolute acoustic measurements across a range of frequencies (Morton 1975; Narins 1982; Waser and Brown 1986; Reiman and Terhune 1993; see text and Table 2 for description). Frequency and intensity parameters that have been employed in studies of MOC-mediated protection studies, from Table 3, are plotted as those sinusoidal

The recordings of natural acoustic environments shown in Table 2 were made under a wide variety of environmental conditions and document ambient environmental noise generated by both biotic and abiotic factors. In spite of this diversity of environmental conditions (e.g., ground cover, vegetation, species assemblages, etc.) and recording techniques, the sources in Table 2 suggest that the great majority of natural acoustic environments are characterized by relatively modest $(<70 \mathrm{~dB}$ SPL) ambient noise levels. Primary sources of abiotic noise include wind, rain, and wave action. Most wind-generated noise has a characteristic spectrum, with the dominant power peaks present at low frequencies (below 200-500 Hz; Brenowitz 1982a; Brown and Schwagmeyer 1984; Brown and Waser 1984; Ryan and Brenowitz 1985). Water-generated noise sources have similar low-frequency spectra with peaks that extend to higher frequencies, though virtually all energy is contained at frequencies below $4.5 \mathrm{kHz}$ (cf Tuttle and Ryan 1982). For example, at frequencies above $2.0 \mathrm{kHz}$, the energy present in any one particular frequency band does not exceed $20 \mathrm{~dB}$ SPL in the water-generated noise spectra figured by Tuttle and Ryan (1982).

The most intense sources of natural ambient noise, however, are biotic (Table 2). Significant biotic noise sources include bird-song and frog and insect cho- stimulus conditions that yielded a protective effect (open diamonds); those sinusoidal stimulus conditions that failed to demonstrate a protective effect (open squares); the noise band exposures against which the MOC demonstrated a protective effect (solid lines), and the noise band conditions against which the MOC had no apparent protective effect (dashed lines). All noise bands (for both environmental noise and protection studies) are plotted as overall dB SPL vs. total frequency range because insufficient details were provided to plot these acoustic conditions in terms of spectral level.

ruses. Indeed, a number of recordings were made with the intention of documenting the noise levels produced by chorusing frogs (e.g., Narins 1982; Schwartz and Wells 1983; Gerhardt and Klump 1988) and insects (e.g., Römer et al. 1989; Páez et al. 1993). Recordings made in the midst of frog choruses account for most of the noisiest reported environments. As noted previously, Narins (1982) documented the highest peak noise levels (Fig. 1) of any source included in Table 2. Within an octave band centered at $2.0 \mathrm{kHz}$, Narins reported that noise levels in a Puerto Rican montane rainforest vary from a minimum of $\sim 48 \mathrm{~dB}$ SPL to a peak of $\sim 92 \mathrm{~dB}$ SPL over a 24 -h period. Noise levels within an octave band centered at $1.0 \mathrm{kHz}$ were somewhat lower, ranging from $\sim 48$ to $\sim 79 \mathrm{~dB}$ SPL. Furthermore, peak sound levels between 1.4 and $2.8 \mathrm{kHz}$ at this locality were maintained near or above $80 \mathrm{~dB}$ SPL from 18.00 to $06.00 \mathrm{~h}$. These relatively intense but spectrally restricted noise levels may be directly attributed to the nocturnal calling of leptodactylid tree frogs because the frequency ranges measured by Narins (1982) encompass the most intense frequency components of the frogs' chorus. The unusually high and sustained noise levels reported by Narins (1982), however, are not typical of all tropical forest sites. For instance, Waser and Brown (1986) found maximum ambient noise levels of only 
about $40 \mathrm{~dB}$ SPL at the rainforest sites of Kibale in Uganda and Kakamega in Kenya. These maximum values for African rainforest sites are comparable to the minimum ambient noise levels reported by $\mathrm{Na}-$ rins (1982) in Puerto Rico. Similarly, Ryan and Brenowitz (1985) reported maximum ambient noise levels of $64 \mathrm{~dB}$ SPL at a lowland tropical forest site in Panama.

The unusually high environmental noise levels reported by Narins (1982) seem, therefore, to be the result of the distinctive frog fauna present in the Luquillo Mountains of Puerto Rico rather than a general characteristic of tropical rainforests. Gerhardt and Klump's (1988) recording of $87 \mathrm{~dB}$ SPL peak ambient noise during a chorus of green tree frogs (made in a pond, near Savannah, Georgia) provides further evidence of an association between high ambient noise levels and chorusing frogs rather than any specific environment. Indeed, maximum ambient noise levels reported in the presence of chorusing frogs are often in excess of $70 \mathrm{~dB}$ SPL, regardless of location (e.g., $71 \mathrm{~dB}$ SPL, Tuttle and Ryan 1982; 80 dB SPL, Schwartz and Wells 1983; 82 dB A, Brenowitz et al. 1984). It is important to bear in mind, however, that in most cases these relatively high sound pressure levels are maintained only within the restricted area (usually a pond or watercourse) near the chorusing frogs. As with all other point sources of noise, the intensity of a localized frog chorus will fall off rapidly with distance (i.e., by at least $6 \mathrm{~dB}$ per doubling of the distance due to spherical spreading, with additional attenuation due to physical obstructions in the environment; Brenowitz 1982a,b; Ryan and Brenowitz 1985).

Additional reports of natural acoustic environments with substantial biotic sound levels come from Páez et al. (1993), who recorded in a Costa Rican rainforest during a full cicada chorus (60-86 dB SPL), from Waser and Waser (1977), who documented noise levels of 70-80 dB SPL during a cicada chorus in the Edea coastal forest of Cameroun, and from Aubin and Jouventin (1998), who recorded at the periphery of a colony of king penguins $(\sim 74 \mathrm{~dB}$ SPL). High peak sound levels were also reported by Brenowitz (1982a), who collected data in a pasture near Ithaca, New York (peak $=76 \mathrm{~dB}$ SPL). Brenowitz (1982a) noted, however, that this frequency-averaged measurement may disproportionately reflect the relatively high intensity of wind-generated, low-frequency background noise. Such noise falls partly outside the range of hearing of many mammals and may be of little import in assessing the vulnerability of the inner ear to acoustic trauma. Conclusions based on the data presented in Table 2 may thus be considered conservative because the frequency-averaged measurements of background noise reviewed here are likely to overestimate the danger posed by natural ambient sound pressure levels. Significantly, data from studies for which absolute sound intensity levels were published for specific frequency ranges demonstrate that the ambient noise levels within any specific frequency band rarely exceed $40 \mathrm{~dB}$ SPL (Fig. 1).

It is important to note that under extreme environmental conditions, noises greater than about 92 $\mathrm{dB}$ SPL (the highest ambient noise level shown in Table 3) probably do occur in nature. Many such instances, however, probably represent sound events that are sufficiently short in duration (e.g., thunder) that they could not activate the "slow" MOC effect that is thought to be responsible for MOC-mediated protection (Liberman and Gao 1995; Reiter and Liberman 1995). Furthermore, if sustained noise levels greater than $92 \mathrm{~dB}$ SPL do occur naturally (e.g., perhaps at the bases of large waterfalls or during intense storms), the environmental conditions represented in Table 3 are diverse enough to suggest that any such "extreme" natural sound environments must be very rare and discontinuously distributed in both time and space.

\section{STIMULUS CONDITIONS NECESSARY TO DEMONSTRATE MOC-BASED PROTECTION}

\section{Criteria for inclusion of protection studies}

A literature search of studies explicitly investigating the role of the efferent tracts in protecting the ear from trauma recovered a large number of primary sources. Table 3 summarizes the findings of the 22 protection studies that form the basis for our subsequent discussion and analysis. The traumatizing stimulus conditions employed in these studies are also plotted in Figure 1, irrespective of their duration (the effects of exposure duration are considered below).

Three experimental studies were excluded from this analysis. Two studies (Horner et al. 1998, 2001) are not considered here because they blocked MOC efferent function pharmacologically rather than through surgical cutting, and may therefore have resulted in deactivation of additional systems that could affect auditory thresholds (e.g., the sympathetic nervous system). A third study, by Chen et al. (2000), is also excluded because the methods and data presented were confusing and inconsistent with the conclusions given by the authors.

Lastly, although there is clearly some overlap with the studies reviewed in this work, we will not consider here the effect known as "conditioning," "toughening," or "priming", (cf. Rajan and Johnstone 1988a,c; Rajan 2001b). In the conditioning paradigm, expo- 


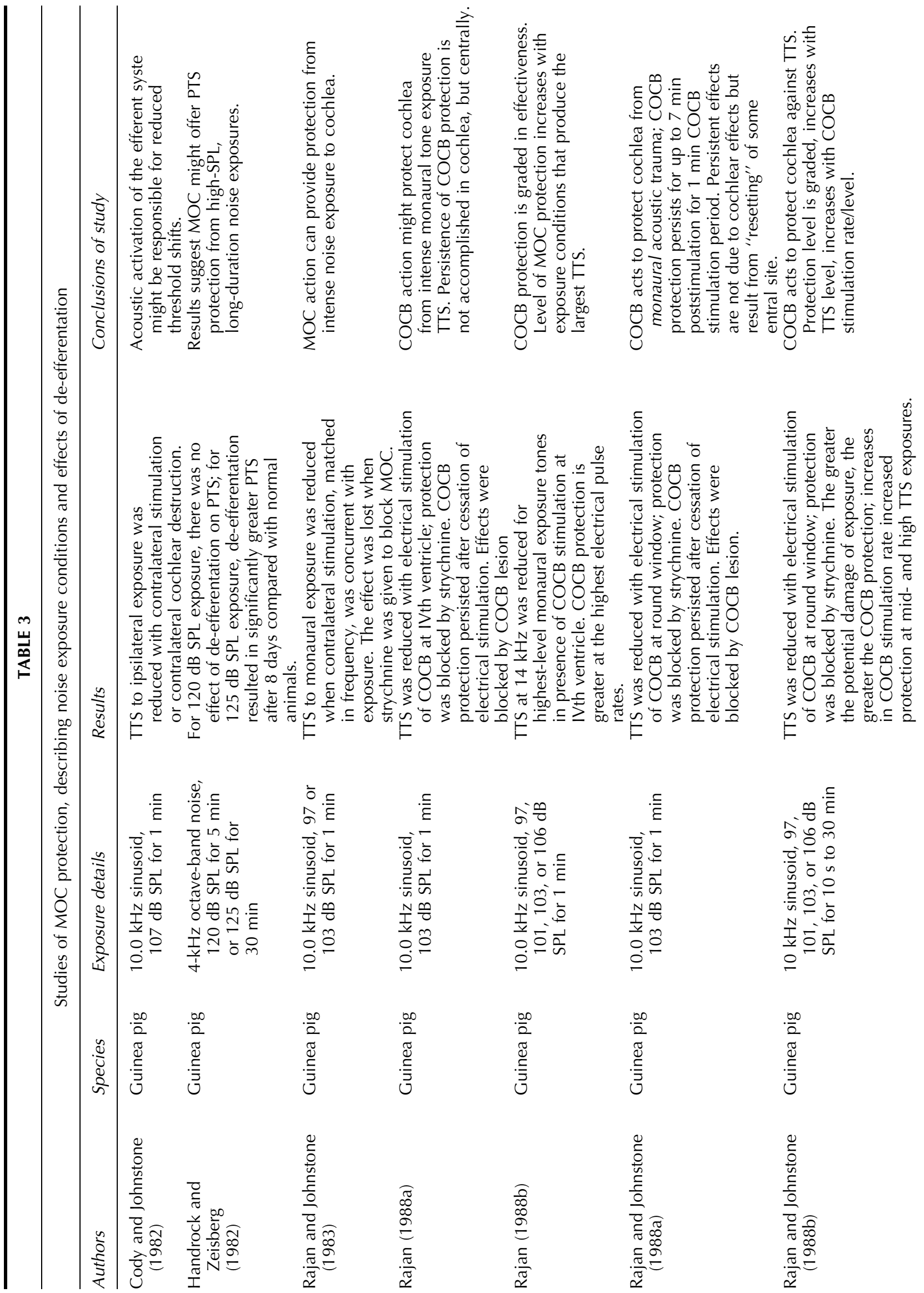




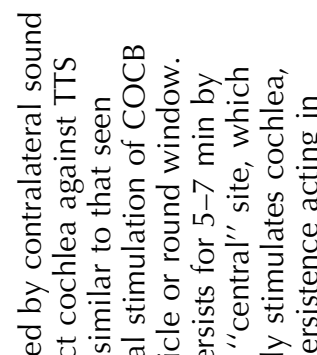

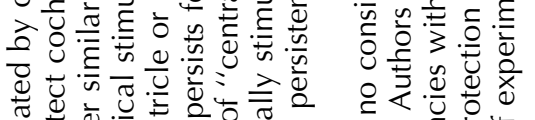

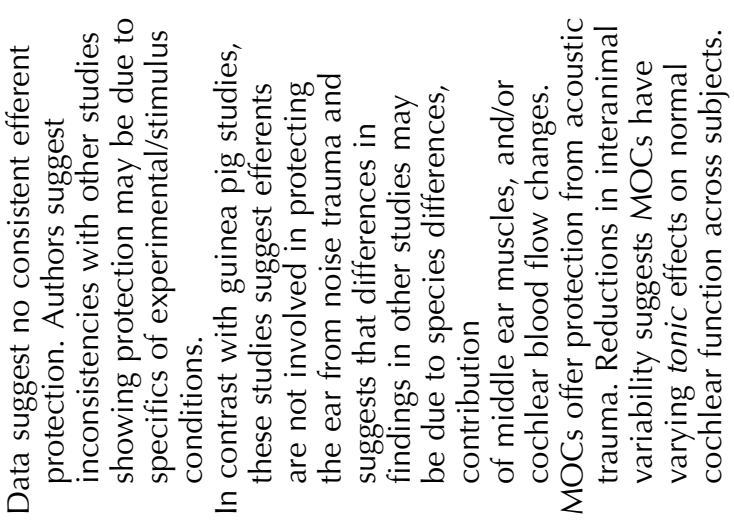

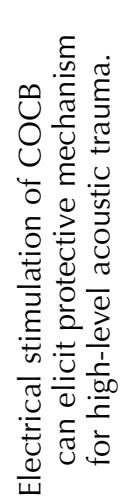

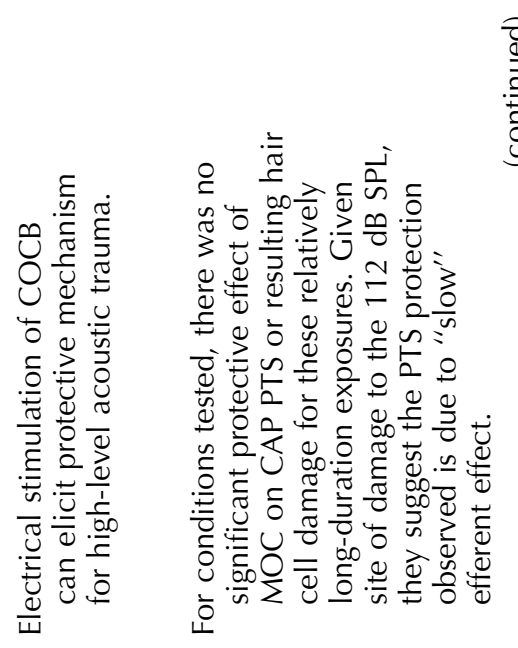

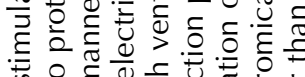

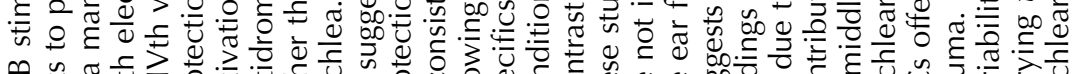

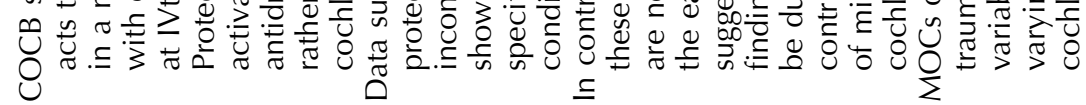

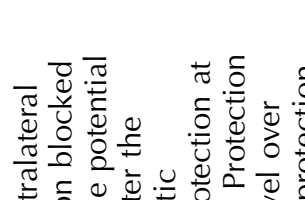

考.

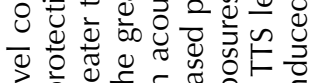

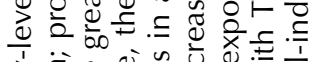

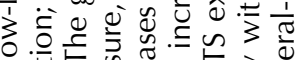

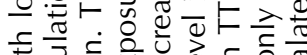

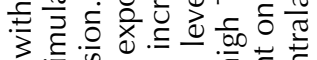

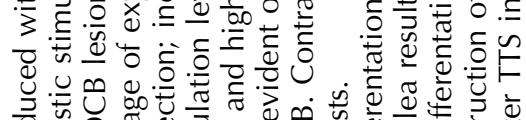

娄

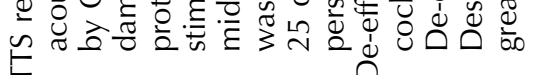

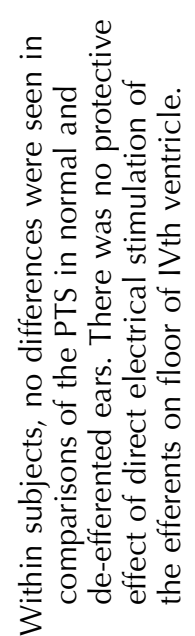

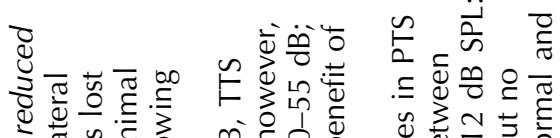

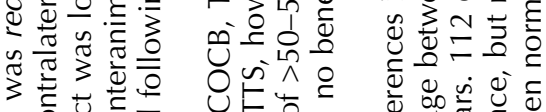

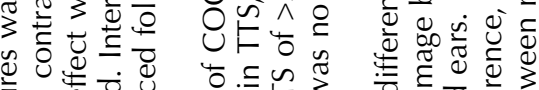

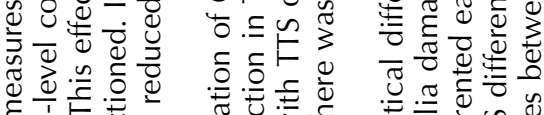

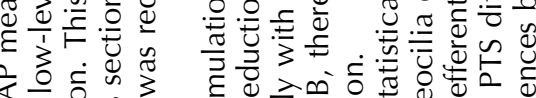

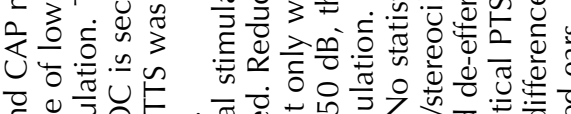

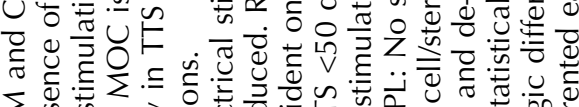

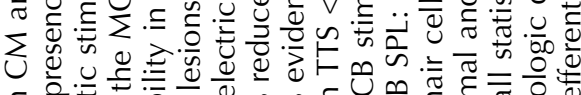

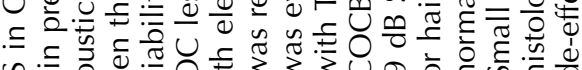

旨.
告

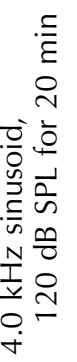

$\frac{\frac{00}{2}}{\frac{0}{2}}$

ש

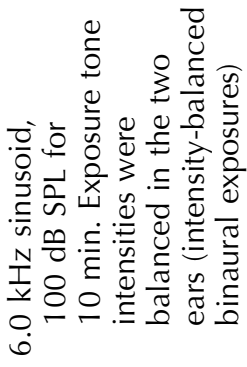

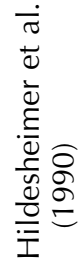

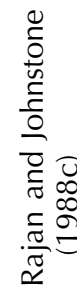

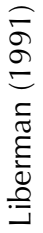

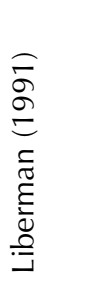

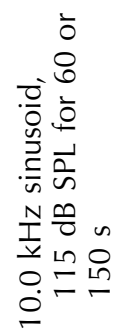

$\frac{\sqrt[0]{2}}{\frac{\pi}{\mathscr{O}}}$

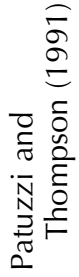

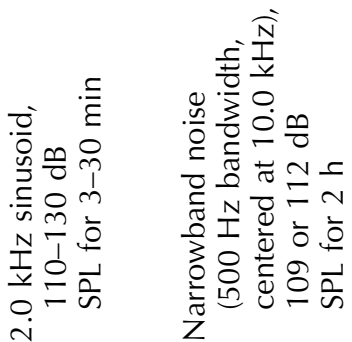

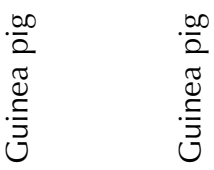

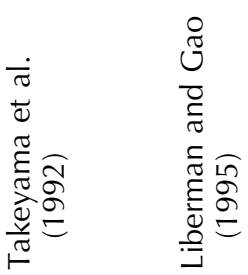




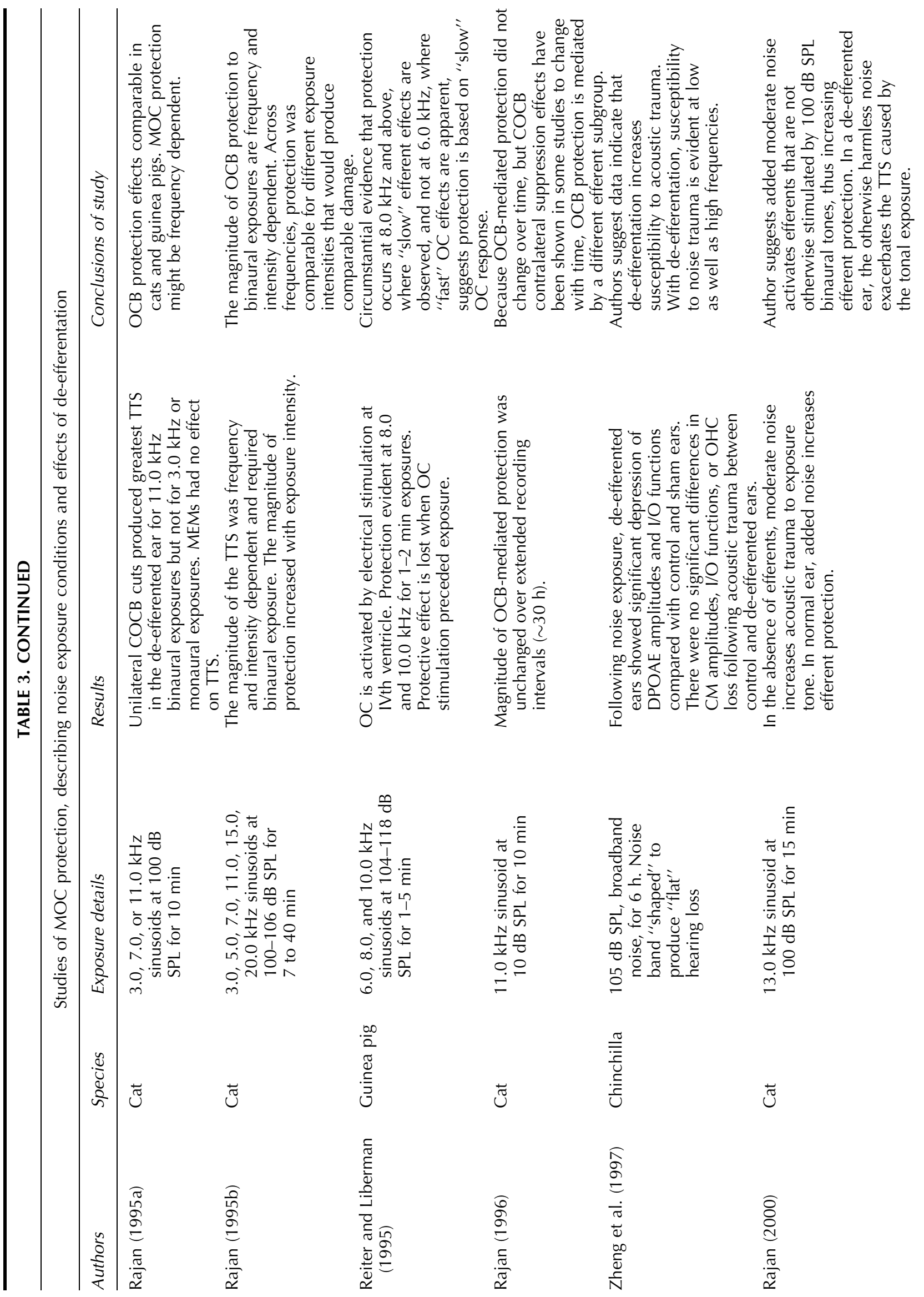


KIRK And Smith: Protection Not a Primary MOC Function

457
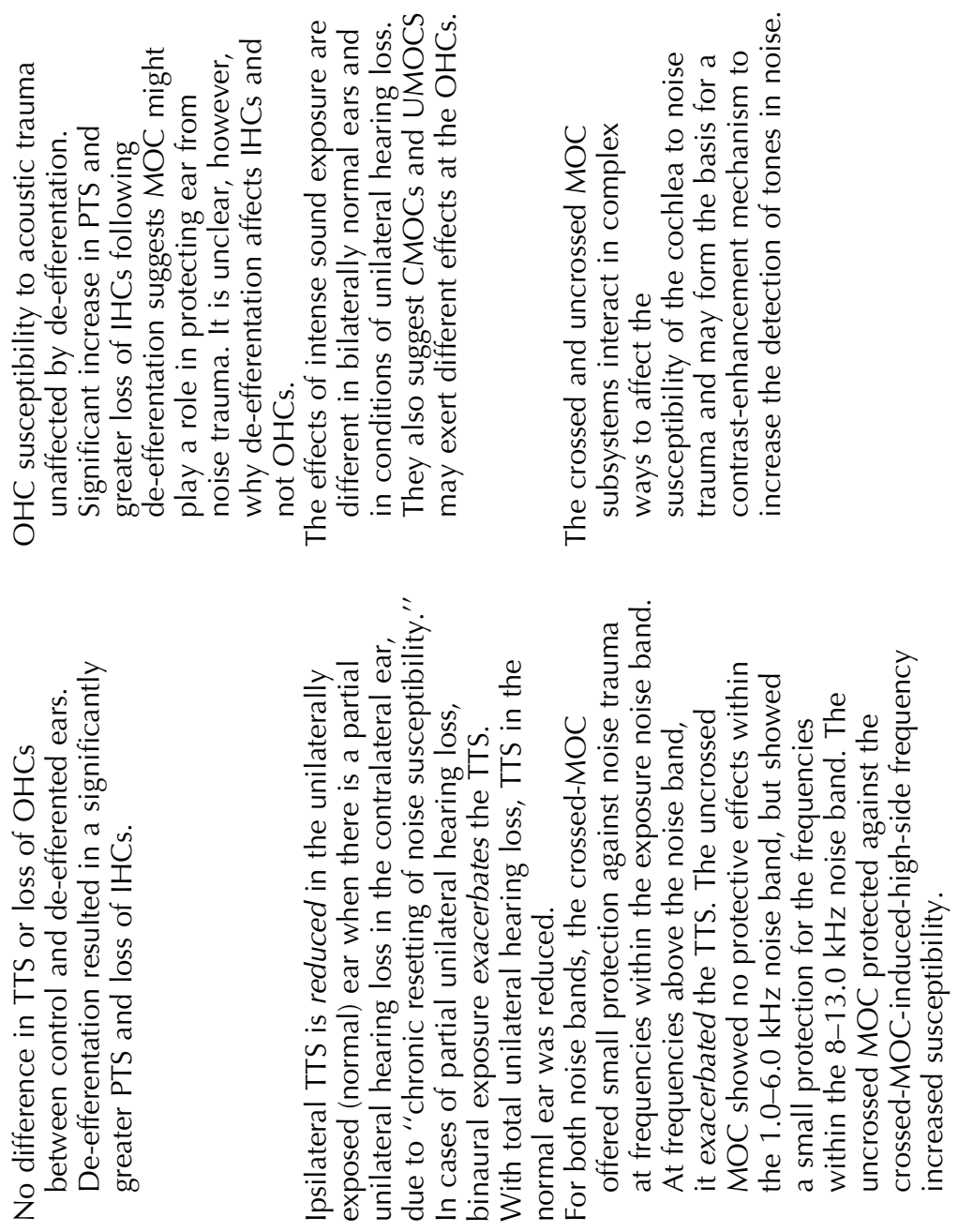

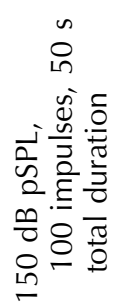

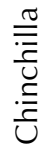

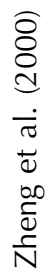

๘

ঊ

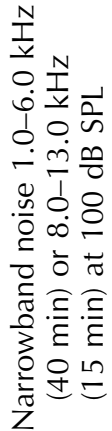

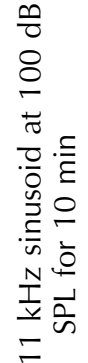

$\frac{\pi}{2}$
$\stackrel{0}{0}$
$\frac{0}{\pi}$
$\frac{0}{\check{\pi}}$ 
sure to one intense sound can reduce the susceptibility of the ear to subsequent intense noise exposures (Canlon et al. 1988). This effect, however, has recently been shown to be unrelated to MOC efferent action (Yamasoba and Dolan 1998; Yoshida et al. 1999; Yoshida and Liberman 2000).

\section{Summary of MOC protection studies}

Table 3 shows that most of the MOC efferent protection studies reviewed here (17 of 22) used highlevel pure tone stimulation to traumatize the ear. Among these "pure tone" studies, the stimulus conditions in which a protective effect was demonstrated (Fig. 1, open diamonds) ranged in frequency from 2.0 to $20.0 \mathrm{kHz}$ and in intensity from 100 to $150 \mathrm{~dB}$ SPL (peak level). Surprisingly, the stimulus conditions that failed to demonstrate MOC protection in similar studies (Fig. 1, open squares) are roughly comparable, ranging from 2.0 to $10.0 \mathrm{kHz}$ and from 97 to $130 \mathrm{~dB}$ SPL. The highly analytic, sinusoidal signals used in these experiments differ radically from the complex frequency spectra found in natural environmental noise (Ryan and Brenowitz 1985; Aubin and Jouventin 1998), although some animal vocalizations, such as the biosonar signals of bats (cf. Griffin 1958) and nonhuman primate calls (cf. Green 1975; Seyfarth et al. 1980), do consist of frequencymodulated signals that are relatively tonal in nature.

Broadband noise stimuli, which more closely approximate the spectral complexity of natural environmental noise, have been used in four protection studies. First, Handrock and Zeisberg (1982) studied the ability of octave-band noise centered at $4.0 \mathrm{kHz}$ to elicit MOC protection in guinea pigs. In this study, the MOC system appeared to reduce noise trauma at $125 \mathrm{~dB}$ SPL but not at $120 \mathrm{~dB}$ SPL exposure. Second, Liberman and Gao (1995) studied the effects of narrowband $(500 \mathrm{~Hz}$ bandwidth) noise centered at $10.0 \mathrm{kHz}$ on compound action potential thresholds in guinea pigs. Ears that had been surgically de- efferented had greater threshold shifts than did normal ears when exposed to $112 \mathrm{~dB}$ SPL noise, but there was no difference in threshold shifts when the ears were exposed to $109 \mathrm{~dB}$ SPL noise. Third, Zheng et al. (1997) compared the effects of $105 \mathrm{~dB}$ SPL broadband noise exposure, shaped to produce a flat threshold shift, in chinchillas with normal and surgically de-efferented ears. Evoked electrophysiological potentials showed no differences in normal and de-efferented ears, although otoacoustic emission amplitudes and input/output measures (measures of outer hair cell function) were depressed in de-efferented ears as compared with normal ears. Zheng et al. concluded that the MOC system decreases the susceptibility of the cochlea to intense noise. Fourth,
Rajan (2001c) exposed cats to $100 \mathrm{~dB}$ SPL narrowband noise at either $1.0-6.0 \mathrm{kHz}(40 \mathrm{~min})$ or 8-13.0 $\mathrm{kHz}$ (15 min). To determine the relative contribution of the crossed and uncrossed MOC tracts to the protective phenomenon, Rajan compared threshold shifts following noise exposure in (1) normal animals and (2) animals in which the different MOC subgroups had been lesioned. The comparisons showed a complex pattern of responses where, depending on the frequency of the temporary threshold shift (TTS) relative to the exposing noise band, the MOC tracts could either protect or exacerbate the threshold shift. The net affect of the MOC action, however, was protective.

One additional study, by Zheng et al. (2000), used extremely high-level [150 dB (peak level) SPL] impulse noise to damage the cochleas of chinchillas. The authors described a relative increase in inner hair cell damage with de-efferentation but no difference in outer hair cell survival following impulse noise exposure. Although these findings are difficult to explain in terms of known MOC innervation patterns and physiology, Zheng et al. (2000) concluded that their data were consistent with the MOC functioning to reduce susceptibility to intense noise exposures.

\section{DISCUSSION: THE MOC SYSTEM DID NOT EVOLVE FOR A PROTECTIVE FUNCTION}

Comparison of natural environmental noise and experimental stimuli

Natural selection occurs as a result of the interaction between an organism's phenotype and a given environmental parameter (sensu lato). Such environmental parameters (e.g., predation, ambient temperature, intraspecific competition, etc.) lead to genetic and morphological changes within populations by favoring differential survival and/or reproductive success among variant phenotypes. In other words, evolution by natural selection is dependent upon environmental effects on organismal fitness. In order to support the hypothesis that a specific environmental condition is either detrimental or beneficial to an organism's fitness, one must first demonstrate that such conditions are indeed present in the organism's natural environment.

The protection hypothesis proposes that the mammalian MOC system has evolved to insulate the organ of Corti from potentially damaging environmental noise. Even a cursory comparison of the data presented in Tables 2 and 3 and represented graphically in Figure 1, however, shows that the intense sound levels (100-150 dB SPL) used to demonstrate MOC-based protection under experimental condi- 
tions are higher (and in most cases substantially higher) than the ambient noise levels in all documented natural acoustic environments. This finding is contrary to the expectations of the protection hypothesis and strongly suggests that the experimental conditions necessary to evoke MOC-mediated protection of the cochlea have no analog in nature. Furthermore, while relatively intense ambient noise levels of about 80-90 dB SPL do occur naturally, these exceptional noise conditions are geographically rare and discontinuously distributed. By contrast, comparative studies of mammalian auditory systems suggest that MOC cochlear efferents are shared by the great majority of placental and marsupial species, which inhabit a diverse range of natural habitats. The fact that a functional MOC system has evidently been retained by most mammalian lineages for at least 175 million years despite considerable ecological differences between species suggests that the selective factors that have maintained the mammalian MOC system must be nearly universal in natural acoustic environments. Relatively high-intensity natural ambient noise ( $\sim 80-90 \mathrm{~dB}$ SPL) clearly does not fit this criterion.

\section{Stimulus intensity and duration}

Based upon the foregoing considerations, it is tempting to reject the protection hypothesis outright. A number of the studies listed in Table 3, however, show protective effects at the lowest sound levels tested, so the critical question remains: What are the lowest sound intensities at which MOC-mediated protection occurs? The answer to this question is likely influenced by the species under consideration due to significant differences in absolute hearing thresholds among mammals (Fay 1988). Nonetheless, Rajan and Johnstone (1988c) have provided evidence that MOC protective effects are elicited in guinea pigs only when the traumatizing acoustic stimulus produces a temporary threshold shift greater than $25 \mathrm{~dB}$, and that the magnitude of the protective effect is directly proportional to the intensity of traumatic stimulus. These results suggest that MOC-mediated protection occurs only in response to very intense acoustic overexposure. Furthermore, in the relatively few species that have been well studied (i.e., cats, guinea pigs, and chinchillas; Table 3), lower intensity thresholds for MOC protection appear to be strongly frequency dependent. For instance, in guinea pigs, Handrock and Zeisberg (1982) and Hildesheimer et al. (1990) found no MOC-mediated protection for 4.0 $\mathrm{kHz}$ sinusoidal or octave-band noise at $120 \mathrm{~dB}$ SPL, whereas Rajan (1988a,b) and Rajan and Johnstone (1983, 1988a,b,c) have consistently demonstrated MOC-mediated protection for $10 \mathrm{kHz}$ tones of only $\sim 100$ dB SPL. Similarly, Rajan (1995b) has shown that the ability to evoke MOC-mediated protective effects at different frequencies is strongly dependent upon both the intensity and the duration of the traumatizing stimulus. In that analysis, lower-intensity and lower-duration thresholds for activation of MOC protection in cats were approximately $100 \mathrm{~dB}$ SPL for $15 \mathrm{~min}$ at $7 \mathrm{kHz}$ compared with $106 \mathrm{~dB}$ SPL for 40 min at $3 \mathrm{kHz}$ (Rajan 1995b).

Because the ability of noise to produce acoustic trauma is dependent on both the intensity and the duration of the traumatizing exposure, any assessment of selective environmental influences on MOC evolution must consider the duration of intense noise sources. The majority of the studies shown in Table 3 exposed test subjects to relatively short-duration stimuli, ranging from about $1 \mathrm{~min}$ to $2 \mathrm{~h}$. Within these narrow exposure parameters and across species, experimentally demonstrated lower-intensity thresholds for MOC-mediated protection are of relatively high intensity. For instance, in guinea pigs the lowest intensities required to activate MOC protection with short-duration stimuli are between 120 and $125 \mathrm{~dB}$ SPL at $4 \mathrm{kHz}$ (Handrock and Zeisberg 1982) and between 109 and $112 \mathrm{~dB}$ SPL at $10.0 \mathrm{kHz}(500 \mathrm{~Hz}-$ wide noise band; Liberman and Gao 1995). Similarly, in cats, short-duration stimuli of 100-106 dB SPL can activate MOC protection for frequencies ranging between 3 and $20 \mathrm{kHz}$, while broadband noise (0.5-40 $\mathrm{kHz}$ ) of $80 \mathrm{~dB}$ SPL causes no acoustic trauma in either de-efferented or efferent-intact ears (Rajan 2000). These data suggest that the lower-intensity threshold for activation of MOC-based protection by short-duration traumatizing stimuli lies somewhere between 80 and $100 \mathrm{~dB}$ SPL for most of the cat's hearing range. Interestingly, for both cats and guinea pigs, the protection threshold is $100-120 \mathrm{~dB}$ above the animal's respective absolute threshold (Fay 1988) at any given frequency.

While most records of environmental noise have intensities well below the lower-intensity thresholds required for MOC protection by short-duration stimuli (Fig. 1), the relatively high ambient noise levels in some natural acoustic environments have considerably longer durations than the traumatizing noise exposures used in most MOC protection studies (Table 3). For instance, at one woodland site in western Australia, Römer et al. (1989) reported ambient noise levels sustained slightly above $60 \mathrm{~dB}$ SPL for at least $3 \mathrm{~h}$ due to chorusing bushcrickets ( $M y$ galopsis). Similarly, in Kibale, Uganda, Waser and Waser (1977) contrasted relatively low ambient noise levels in the forest canopy (between 40 and $50 \mathrm{~dB}$ SPL across a 24-h cycle), with noise levels near the ground, which may be sustained between about 65 and $75 \mathrm{~dB}$ SPL for approximately $8 \mathrm{~h}$ in the presence of 
chorusing cicadas. Narins' (1982) recordings of biotic noise in the montane rainforests of Puerto Rico, however, provide a record of not only the most intense known natural noise levels, but also the longest sustained levels of intense noise. For nearly $12 \mathrm{~h}$ each evening, noise levels between 1.4 and $2.8 \mathrm{kHz}$ ranged from slightly below $80 \mathrm{~dB}$ SPL to slightly above $90 \mathrm{~dB}$ SPL as a result of chorusing frogs. While Narins' (1982) measurements are unique in terms of their intensity and duration, it is important to bear in mind that these data represent the average peak sound levels measured over 10-s intervals and sample only the narrow frequency range that encompasses the most intense component of the frog chorus.

These data on sustained noise in natural environments raise the question of whether noise levels that are of lower intensity but longer duration than the experimental conditions summarized in Table 3 may activate the protective effects of the MOC system. Unfortunately, very few studies of MOC protection have been carried out at moderate sound intensities of longer duration. This question is relevant to studies of MOC evolution because the most extreme natural noise levels (e.g., 80-90 dB SPL caused by chorusing frogs and insects) shown in Table 3 approach levels that could potentially result in permanent acoustic trauma for some mammals with intact MOC efferent systems. In chinchillas, for example, a number of studies have demonstrated susceptibility to permanent threshold shifts (PTS) as a result of long-term (6-150 days continuous), moderate-intensity (82-95 dB SPL) noise exposure (e.g., Mills 1973; Ward et al. 1981; Bohne et al. 1987; Clark et al. 1987). Because of their comparative susceptibility to acoustic trauma (e.g., Mitchell 1976; Décory et al. 1992), chinchillas may not represent the best general model for the vulnerability of the mammalian auditory system. Thus, any conclusions based upon chinchillas can be regarded as conservative.

In the experimental design that perhaps best approximates an extreme natural noise environment, Bohne et al. (1987) exposed chinchillas to $4 \mathrm{kHz}$ octave-band noise at 80-86 dB SPL for $6 \mathrm{~h}$ per day over a 36-day period. Under these test conditions, many test animals (36\% at $80 \mathrm{~dB}$ SPL; $50 \%$ at $86 \mathrm{~dB}$ SPL) showed evidence of high-frequency lesions of the organ of Corti at the end of the experiment. Similarly, Mills (1973) provided behavioral evidence of moderate PTS (8-13 dB) in chinchillas exposed to continuous $4.0 \mathrm{kHz}$ octave-band noise at $86 \mathrm{~dB}$ SPL for 9 days. Chinchillas exposed to $80 \mathrm{~dB}$ SPL noise under the same experimental design, however, showed no evidence of PTS. These data suggest that $80 \mathrm{~dB}$ SPL is probably near the lower limit at which PTS could be expected to occur under natural conditions, since permanent acoustic trauma due to lower sound levels would likely require exposure durations that are not found in any natural acoustic environment. Because sustained noise levels significantly greater than $80 \mathrm{~dB}$ SPL are very rare in nature, we suggest that most natural acoustic environments would probably not cause permanent acoustic trauma to chinchillas and, by extension, most other mammals. Even if some unusual natural acoustic environments (e.g., the Luquillo Mountains of Puerto Rico; Narins 1982) have noise intensities that could potentially traumatize the cochleas of MOC-intact animals, it nevertheless remains clear that the stimulus conditions known to elicit MOC protection in experimental settings differ substantially from the noise characteristics of all natural acoustic environments.

\section{The effects of internally generated noise}

This review has thus far considered only the external acoustic environment, although several studies have demonstrated that the medial efferent system can have a significant effect on neural responses to internally generated sounds (Kawase and Liberman 1993; Kawase et al. 1993; Cazals and Huang 1996; Popelár et al. 1997; Lima da Costa et al. 1997). Given the extreme sensitivity of the mammalian auditory receptor, the cochlea responds to internal acoustic events created by blood circulation, heart contractions, respiration, body movements, and chewing. The acoustic energy for these signals, however, is low in frequency and intensity (cf. Cazals and Huang 1996; Lima da Costa et al. 1997), and the cochlear response to these signals might represent a part of the measured "spontaneous activity" of the auditory nerve (Guinan and Gifford 1988; Cazals and Huang 1996). Gnathosonic measures of the sound generated by normal dental occlusion shows that virtually all spectral energy is found in bands below $400 \mathrm{~Hz}$, with the majority being present between 50 and $150 \mathrm{~Hz}$ (Hedzelek and Hornowski 1998; Sano et al. 2002). These findings suggest that chewing sounds are unlikely to have a significant deleterious impact on higher-frequency thresholds (i.e., at frequencies where MOC efferents are present in the cochlea).

Likewise, it is theoretically possible that the MOC system could have evolved as a protective mechanism to counteract the deleterious effects of an animal's own intense vocalizations. While a detailed treatment of this possibility is outside the scope of this review, we feel that this scenario is unlikely for several reasons. First, the mammalian auditory system is already known to exhibit a means of reducing the effects of internally produced vocalizations in the form of the middle ear reflex. The middle ear reflex is activated by vocalizations and/or speech (Carmel and Starr 
1963; Henson 1965) and can produce a significant attenuation of an auditory signal (i.e., by as much as 10-30 dB) before it can be transmitted to the cochlea.

Second, there is little evidence for correspondence between the frequency of an animal's vocalizations and patterns of MOC innervation of the organ of Corti. For instance, in many echolocating bats (where ultrasonic pulses reach $>120 \mathrm{~dB}$ SPL at $\sim 50 \mathrm{kHz}$ ), MOC innervation is relatively uniform throughout the organ of Corti (Griffin 1958; Henson 1965). If the MOC system was necessary for protection from the intense vocalizations produced by these species, then greater MOC innervation at the acoustic fovea (which includes the region of the basilar membrane responsible for transducing the dominant frequency of the vocalization) would be expected.

Third, the ability to produce intense vocalizations is not always associated with the presence of a functional MOC efferent system. Of the three genera of mammals currently known to lack an MOC system, two are microchiropteran bats (Hipposideros and Rhinolophus) that produce extremely high-intensity vocalizations (>120 dB SPL) like many other microchiropterans. It therefore seems unlikely that MOC innervation of the cochlea would have been lost in these two genera if the MOC system plays a role in protecting the inner ear from trauma caused by highintensity vocalizations.

Finally, some species that are known to have a highly developed MOC system do not produce intense vocalizations. For example, the vocal repertoire of domestic cats appears rather limited and may function primarily between conspecifics at close range. High-intensity calls that might serve to group distant conspecifics seem to be entirely lacking (Wemmer and Scow 1977).

\section{If not protection, why did the MOC system} evolve?

The primary goal of this article has been to answer one question: Did the MOC system evolve as a mechanism to protect the cochlea from acoustic trauma caused by high-intensity natural environmental noise? Given the results of our analysis discussed above, the answer can only be "no." The substantial MOC protection literature (Table 3), however, clearly demonstrates that destruction of the MOC system increases the cochlea's susceptibility to acoustic trauma from very high-intensity tones under experimental conditions. There can be little doubt that this protective effect is real, given the control and repeatability of the supporting data. How then can these data be reconciled with our conclusions?

The explanation for the repeated protection finding can be found in the fact that the action of the
MOC system is suppressive in nature (Fex 1967; Konishi and Slepian 1970; Wiederhold and Kiang 1970; Buño 1978; Mountain 1980; Siegel and Kim 1982; Liberman 1989; Warren and Liberman 1989; Kawase and Liberman 1993; Kawase et al. 1993; Cazals and Huang 1996; Lima da Costa et al. 1997; Nuttall et al. 1997). In general, the magnitude of the suppressive action of MOC efferents on the various cochlear responses is proportional to the intensity of the stimulus (whether acoustic or electric) activating the MOC system (cf. Warren and Liberman 1989). Importantly, the magnitude of MOC-mediated suppression increases with the level of afferent neural activity (Guinan and Stankovic 1996). Guinan and Stankovic (1996) have shown that MOC activity can produce a reduction, in the largest case, in singlefiber discharge rate equivalent to a $50 \mathrm{~dB}$ attenuation of the input stimulus at BF. The attenuation, which was greatest in low-spontaneous-rate fibers, increased to stimulation levels of 50-75 dB SPL, then decreased rapidly with further increases in stimulation. In the present context, assuming that MOC activity elicited by sound is at least qualitatively similar to that elicited by electrical stimulation, MOC action would have the net effect of reducing the level of the intense noise exposure, thereby reducing the resulting damage.

One significant limitation of most previous investigations of the MOC efferent system is the failure to distinguish between the actual biological role of a system (i.e., the purpose for which the system evolved) and the performance of the system in a strictly controlled experimental context. Most experimental studies of the MOC system refer only to its "function" (e.g., Maison and Liberman 2000) and do not consider the actual selective variables that may have been involved in the evolution of the MOC system. From the perspective of evolutionary biology, "function" is an imprecise term that refers to the myriad roles that may be played by a system in a variety of contexts. As noted above, in order to help delineate the biological role of a system, it is first necessary to determine whether the stimulus conditions necessary to evoke a specific function are routinely encountered in nature. In the case of the protection hypothesis, most of the supporting evidence for protection (Table 3) clearly fails this test in light of the cumulative evidence (Table 2) that natural acoustic environments do not demonstrate sustained levels of noise that are sufficiently intense to activate experimentally demonstrated MOC protective effects. "Protective" effects thought to be mediated by MOC action (Table 3) may therefore represent epiphenomena that arise from the inherently suppressive role of the MOC system (cf. Borg et al. 1995). 
These conclusions beg an additional question: If the MOC system did not evolve to protect the inner ear from acoustic trauma, then what is the biological role of the MOC system in mammalian hearing? As is clear from the data shown in Table 2 and Figure 1, all natural acoustic environments are characterized by noise spanning a wide range of frequencies. This finding is particularly relevant for tropical forested habitats, which tend to have diverse insect and vertebrate faunas that rely on acoustic signals for a variety of communicatory functions. The sources cited in Table 2 further indicate that abiotic noise is a nearubiquitous feature of natural acoustic environments. The combined effects of both wind and water ensure that low-intensity, relatively broadband noise is present in nearly all natural environments, suggesting that the biggest problem posed by natural ambient noise may be the masking of biologically relevant acoustic signals. This universal distribution and predominantly low-to-moderate intensity of natural environmental noise thus supports the hypothesis that the MOC system evolved in the context of unmasking transient stimuli, rather than protecting the inner ear from intense noise levels. In this context, it is not surprising that noisy, relatively broadband signals, like those present in natural environments, are among the most effective in stimulating MOC efferent activity (Warren and Liberman 1989). Indeed, we expect that mammals (like most vertebrate lineages) have experienced significant selective pressure to segregate biologically relevant acoustic signals from irrelevant background noise (Waser and Brown 1984; Brown and Waser 1988; Fay and Popper 2000).

\section{SUMMARY OF FINDINGS}

Ambient noise in all natural acoustic environments is significantly lower in intensity than the experimental conditions that are known to evoke an MOC-based protective effect. The very intense traumatizing stimuli [100-150 dB SPL (peak level), primarily sinusoidal tones] used in all short-duration studies demonstrating MOC-mediated protection simply have no natural analog. Although longer duration, relatively highintensity ( 80-90 dB SPL) noise has been documented in a small number of natural acoustic environments, these noise conditions are probably not sufficient to activate the protective effects of the MOC system. Even if such relatively high-intensity noise environments can activate MOC protective effects, the rarity of such noise environments suggests that their role in the evolution of the mammalian MOC system would have been small. The substantial discrepancy between the characteristics of natural ambient noise and the experimental conditions nec- essary to evoke MOC-based protection provides strong evidence that the MOC system did not evolve to protect the inner ear from acoustic trauma.

\section{ACKNOWLEDGMENTS}

The authors are greatly indebted to Drs. Miriam and Bill Henson, Emily Buss, Marc Bassim, and two anonymous reviewers for comments on the manuscript. Discussions with Drs. Charles H. Brown, David B. Moody, and Peter M. Narins were most helpful in interpreting the ambient noise and animal vocalization literatures. We are also thankful for insightful discussions with Drs. Evan Relkin, J.J. Guinan, Jr., Bertrand Delgutte, and David Mountain when this work was first presented at the Midwinter Research Meeting of the Association for Research in Otolaryngology (January 2002). Ann Tamariz rendered editorial assistance. This work was supported in part by a James B. Duke graduate fellowship and a National Science Foundation graduate research fellowship to ECK and by NIH-NIDCD grant DC01692 to DWS.

\section{REFERENCES}

Aschoff A, Ostwald J. Different origins of cochlear efferents in some bat species, rats, and guinea pigs. J. Comp. Neurol. 264:56-72, 1987.

Aschoff A, Ostwald J. Distribution of cochlear efferents and olivocochlear neurons in the brainstem of rat and guinea pig. Exp. Brain Res. 71:241-251, 1988.

Aschoff A, Müller M, Отт H. Origin of cochlea efferents in some gerbil species. Exp. Brain Res. 71:252-261, 1988.

Aubin T, Jouventin P. Cocktail-party effect in king penguin colonies. Proc. R. Soc. Lond. B Biol. Sci. 265:1665-1673, 1998.

Azeredo WJ, Kliment ML, Morley BJ, Relkin E, Slepecky NB, Sterns WB, WARR WB, WeEkLY JM, WoODS CI. Olivocochlear neurons in the chinchilla: a retrograde fluorescent labeling study. Hear. Res. 134:57-70, 1999.

Bishop AL, Henson Jr, OW. The efferent cochlear projections of the superior olivocochlear complex in the mustached bat. Hear. Res. 31:175-182, 1987.

Bishop AL, Henson Jr, OW. The efferent auditory system in Doppler compensating bats. In: Nachtigall PE, Moore PWB (Eds.) Animal Sonar: Processes and Performance. Plenum Press, New York, pp 307-310, 1988.

Bohne BA, Yohman L, Gruner MM. Cochlear damage following interrupted exposure to high-frequency noise. Hear. Res. 29:251-264, 1987.

Borg E, Canlon B, Engström B. Noise induced hearing loss: literature review and experiments in rabbits. Scand. Audiol. 24(Suppl. 40):1-147, 1995.

BREnOwITz EA. The active space of red-winged blackbird song. J. Comp. Physiol. 147:511-522, 1982a.

BRENOWITZ EA. Long-range communication of species identity by song in the red-winged blackbird. Behav. Ecol. Sociobiol. 10:29$38,1982 \mathrm{~b}$.

Brenowitz EA, Wilczynski W, Zakon HH. Acoustic communication in spring peepers. J. Comp. Physiol. A 155:585-592, 1984.

Brown CH, Schwagmeyer PL. The vocal range of alarm calls in thirteen-lined ground squirrels. Z. Tierpsychol. 65:273-288, 1984. 
BRown CH, WASER PM. Hearing and communication in blue monkeys (Cercopithecus mitis). Anim. Behav. 32:66-75, 1984.

BROWN CH, WASER PM. Environmental influences on the structure of primate vocalizations. In: Todt O, Goedeking P, Symmes D (Eds.) Primate Vocal Communication. Springer-Verlag, Berlin, pp 51-66, 1988.

Brown MC, NutTall AL, MASTA RI. Intracellular recordings from cochlear inner hair cells: effects of stimulation of the crossed olivocochlear efferents. Science 222:69-71, 1983.

BRuns V. Peripheral auditory tuning for fine frequency analysis by the CF-FM bat, Rhinolophus ferrumequinum. I. Mechanical specializations of the cochlea. J. Comp. Physiol. 106:77-86, 1976a.

BRUNS V. Peripheral auditory tuning for fine frequency analysis by the CF-FM bat, Rhinolophus ferrumequinum. II. Frequency mapping in the cochlea. J. Comp. Physiol. 106:87-97, 1976b.

BRuns V, Schmieszek E. Cochlear innervation in the greater horseshoe bat: Demonstration of an acoustic fovea. Hear. Res. 3:2743, 1980.

Bruns V, Müller M, Hofer W, Heth G, Nevo E. Inner ear structure and electrophysiological audiograms of the subterranean mole rat, Spalax ehrenbergi. Hear. Res. 33:1-10, 1988.

BuÑo W. Auditory nerve fiber activity influenced by contralateral ear sound stimulation. Exp. Neurol. 59:62-74, 1978.

Burda H, Bruns V, Nevo E. Middle ear and cochlear receptors in the subterranean mole rat, Spalax ehrenbergi. Hear. Res. 39:225230, 1989.

Campbell JP, Henson MM. Olivocochlear neurons in the brainstem of the mouse. Hear. Res. 35:271-274, 1988.

Canlon B, Borg E, Flock A. Protection against noise trauma by preexposure to a low level acoustic stimulus. Hear. Res. 34:197-200, 1988.

Carmel PW, Starr A. Acoustic and nonacoustic factors modifying middle-ear muscle activity in waking cats. J. Neurophysiol. 26:598-616, 1963.

Cazals Y, Huang ZW. Average spectrum of cochlear activity: A possible synchronized firing, its olivo cochlear feedback and alterations under anesthesia. Hear. Res. 101:81-92, 1996.

Chen T-J, Chen S-S, Hsien Y-L. Evaluating the protective role of the olivocochlear bundle against overexposure in rats by using Fos immunohistochemistry. J. Neurol. Sci. 177:104-113, 2000.

Clark WW, Bohne BA, Boettcher FA. Effect of periodic rest on hearing loss and cochlear damage following exposure to noise. J. Acoust. Soc. Am. 82:1253-1264, 1987.

Cody AR, Johnstone BM. Temporary threshold shift modified by binaural acoustic stimulation. Hear. Res. 6:199-206, 1982.

Dannhof BJ, Bruns V. The organ of Corti in the bat Hipposideros bicolor. Hear. Res. 53:253-268, 1991.

Décory L, Dancer AL, Aran J-M. Species differences and mechanisms of damage. In: Dancer A, Henderson D, Salvi RJ, Hamernik RP (Eds.) Noise-induced Hearing Loss. Mosby Year Book, St. Louis, MO, pp 73-88, 1992.

Dolan DF, Nuttall AL. Masked cochlear whole-nerve response intensity functions altered by electrical stimulation of the crossed olivocochlear bundle. J. Acoust. Soc. Am. 83:1081-1086, 1988.

EPA (Environmental Protection Agency). Report to the President and Congress on noise. Senate Document 92-63, 1972. U.S. GPO, Washington, D.C.

FAY RR. Hearing in Vertebrates. HiIl-Fay Assoc., Winnetka, IL, 1988.

FAY RF, POPPER AN. Evolution of hearing in vertebrates: the inner ears and processing. Hear. Res. 149:1-10, 2000.

FEx J. Efferent inhibition in the cochlea related to hair cell DC activity: study of postsynaptic activity of the crossed olivocochlear fibers in the cat. J. Acoust. Soc. Am. 41:666-675, 1967.

Fritzsch B. The water-to-land transition: evolution of the tetrapod basilar papilla, middle ear and auditory nuclei. In: Webster DB,
Fay RR, Popper AN (Eds.) The Evolutionary Biology of Hearing. Springer-Verlag, New York, pp 351-375, 1992.

Fritzsch B. On the role played by ontogenetic remodeling and functional transformation in the evolution of terrestrial hearing. Brain Behav. Evol. 50:38-49, 1997.

GerhardT HC, KLumP GM. Masking of acoustic signals by the chorus background noise in the green tree frog: a limitation on mate choice. Anim. Behav. 36:1247-1249, 1988.

GREen S. Variation of vocal pattern with social situation in the Japanese monkey (Macaca fuscata): a field study. In: Rosenblum LA (Eds.) Primate Behavior, Vol. 4. Academic Press, New York, pp 1-102, 1975.

GRIFFIN DR. Listening in the Dark. Yale University Press, New Haven, CT, 1958.

Guinan Jr JJ. Physiology of olivocochlear efferents. In: Dallos P, Popper AN, Fay RR (Eds.) The Cochlea. Springer-Verlag, New York, pp 435-502, 1996.

GUINAN Jr JJ, GIFFORD ML. Effects of electrical stimulation of efferent olivocochlear neurons on cat auditory-nerve fibers. III. Tuning curves and thresholds at CF. Hear. Res. 37:29-46, 1988.

Guinan Jr JJ, Stankovic KM. Medial efferent inhibition produces the largest equivalent attenuations at moderate to high sound levels in cat auditory nerve fibers. J. Acoust. Soc. Am. 100:16801690, 1996.

Guinan Jr JJ, Warr WB, Norris BE. Differential olivocochlear projections from lateral versus medial zones of the superior olivary complex. J. Comp. Neurol. 221:358-370, 1983.

Handrock M, Zeisberg J. The influence of the efferent system on adaptation, temporary and permanent threshold shift. Arch. Otorhinolaryngol 234:191-195, 1982.

Hedzelek W, Hornowski T. The analysis of occlusal sounds in patients with periodontal diseases and gnathic dysfunction. J. Oral Rehabil. 25:139-145, 1998.

Henson Jr, OW. The activity and function of the middle ear muscles in echolocating bats. J. Physiol. (Lond.) 180:871-887, 1965.

Hildesheimer M, Makai E, Muchnik C, Rubenstein M. The influence of the efferent system on acoustic overstimulation. Hear. Res. 43:263-268, 1990.

Horner KC, Higueret D, Cazals Y. Efferent-mediated protection of the cochlear base from acoustic overexposure by low doses of lithium. Eur. J. Neurosci. 10:1524-1527, 1998.

Horner KC, Giraudet F, Lucciano M, Cazals Y. Sympathectomy improves the ear's resistance to acoustic trauma-could stress render the ear more sensitive? Eur. J. Neurosci. 13:405-408, 2001.

Kawase T, Delgutte B, Liberman MC. Antimasking effects of the olivocochlear reflex. II. Enhancement of auditory-nerve response to masked tones. J. Neurophysiol. 70:2533-2548, 1993.

Kawase T, Liberman MC. Antimasking effects of the olivocochlear reflex. I. Enhancement of compound action potentials to masked tones. J. Neurophysiol. 70:2519-2532, 1993.

Konishi T, Slepian JZ. Effects of the electrical stimulation of the crossed-olivocochlear bundle on cochlear potentials recorded with intracochlear electrodes in guinea pigs. J. Acoust. Soc. Am. 49:1762-1769, 1970.

Kumar S, Hedges SB. A molecular timescale for vertebrate evolution. Nature 392:917-920, 1998.

Ladhams A, Pickles JO. Morphology of the monotreme organ of Corti and macula lagena. J. Comp. Neurol. 366:335-347, 1996.

Liberman MC. Rapid assessment of sound-evoked olivocochlear feedback: suppression of compound action potential by contralateral sound. Hear. Res. 38:47-56, 1989.

LiBerman MC. The olivocochlear efferent bundle and susceptibility of the inner ear to acoustic injury. J. Neurophysiol. 65:123-132, 1991.

Liberman MC, GaO WY. Chronic cochlear de-efferentation and susceptibility to permanent acoustic injury. Hear. Res. 90:158$168,1995$. 
Liberman MC, Guinan Jr JJ. Feedback control of the auditory periphery: anti-masking effects of middle ear muscles vs. olivocochlear efferents. J. Commun. Disord. 31:471-483, 1998.

Liberman MC, Dodd LW, Pierce S. Afferent and efferent innervation of the cochlea: quantitative analysis with light and electron microscopy. J. Comp. Neurol. 301:443-460, 1990.

Liberman MC, Puria S, Guinan Jr JJ. The ipsilaterally evoked olivocochlear reflex causes rapid adaptation of the $2 f 1-f 2$ distortion product otoacoustic emission. J. Acoust. Soc. Am. 99:2572-3584, 1996.

Lima da Costa D, Chibois A, Erre J-P, Blanchet C, Charlet de Sauvage R, Aran J-M. Fast, slow, and steady-state effects of contralateral acoustic activation of the medial olivocochlear efferent system in awake guinea pigs: action of gentamicin. J. Neurophysiol. 78:1826-1836, 1997.

Luz GA, Sмiтн JB. Reactions of pronghorn antelope to helicopter overflight. J. Acoust. Soc. Am. 59:1514-1515, 1976.

Maison SF, Liberman MC. Predicting vulnerability to acoustic injury with a noninvasive assay of olivocochlear reflex strength. J. Neurosci. 20:4701-4707, 2000.

MAY BJ, McQuone SJ. Effects of bilateral olivocochlear lesions on pure-tone intensity discrimination in cats. Aud. Neurosci. 1:385-400, 1995.

Mills JH. Temporary and permanent threshold shifts produced by nine-day exposures to noise. J. Speech Hear. Res. 16:426-438, 1973.

Mitchell C. Susceptibility to auditory fatigue: Comparison of changes in cochlear nerve potentials in the guinea pig and chinchilla. J. Acoust. Soc. Am. 60:418-422, 1976.

MorTOn ES. Ecological sources of selection on avian sounds. Am. Nat. 109:17-34, 1975.

Mountain DC. Changes in endolymphatic potential and crossed olivocochlear bundle stimulation alter cochlear mechanics. Science 210:71-72, 1980.

NADOL Jr JJ. Serial section reconstruction of the neural poles of hair cells in the human organ of Corti. II. Outer hair cells. Laryngoscope 93:780-791, 1983.

NADOL Jr JJ. Synaptic morphology of inner and outer hair cells of the human organ of Corti. J. Electron Microsc. Tech. 15:187196, 1990.

NADOL Jr JJ, Burgess BJ. Morphology of synapses at the base of hair cells in the organ of Corti of the chimpanzee. Ann. Otol. Rhinol. Larygol. 99:215-220, 1990.

NARINS PM. Effects of masking noise on evoked calling in the Puerto Rican coqui (Anura: Leptodactylidae). J. Comp. Physiol. 147:439-446, 1982.

National Park Service. Report on the Effects of Aircraft Overflights on the National Park System: Executive Summary Report to Congress Appendixes, United States Department of the Interior, U.S. GPO, Washington, D.C., 1995.

Nieder P, Nieder I. Crossed olivocochlear bundle: Electrical stimulation enhances masked neural responses to loud clicks. Brain Res. 21:135-137, 1970.

Nuttall AL, Guo M, Ren T, Dolan DF. Basilar membrane velocity noise. Hear. Res. 114:35-42, 1997.

OdendaAl FJ, Bull CM, Telford SR. Influence of the acoustic environment on the distribution of the frog Ranidella riparia. Anim. Behav. 34:1836-1843, 1986.

Ostwald J, Aschoff A. Only one nucleus in the brainstem projects to the cochlea in horseshoe bats: the nucleus olivo-cochlearis. In: Nachtigall PE, Moore WB (Eds.) Animal Sonar: Processes and Performance. Plenum Press, New York, pp 347-350, 1988.

PÁez VP, Bock BC, Rand AS. Inhibition of evoked calling of Dendrobates pumilio due to acoustic interference from cicada calling. Biotropica 25:242-245, 1993.
Patuzzi RB, Thompson ML. Cochlear efferent neurones and protection against acoustic trauma: protection of outer hair cell receptor current and interanimal variability. Hear. Res. 54:45$58,1991$.

Penna M, Solis R. Frog call intensities and sound propagation in the South American temperate forest region. Behav. Ecol. Sociobiol. 42:371-381, 1998.

Popelár J, Lima da Costa D, Erre J-P, Avan P, Aran J-M. Contralateral suppression of the ensemble background activity of the auditory nerve in awake guinea pigs: effects of gentamicin. Aud. Neurosci. 3:425-433, 1997.

Price AJ. Community noise survey of greater Vancouver. J. Acoust. Soc. Am. 52:488-492, 1971.

Rajan R. Effect of electrical stimulation of the crossed olivocochlear bundle on temporary threshold shifts in auditory sensitivity. I. Dependence on electrical stimulation parameters. J. Neurophysiol. 60:549-568, 1988a.

RAJAN R. Effect of electrical stimulation of the crossed olivocochlear bundle on temporary threshold shifts in auditory sensitivity. II. Dependence on the level of temporary threshold shifts. J. Neurophysiol. 60:569-579, 1988b.

RAJAN R. Involvement of cochlear efferent pathways in protective effects elicited with binaural loud sound exposure in cats. J. Neurophysiol. 74:582-597, 1995a.

Rajan R. Frequency and loss dependence of the protective effects of the olivocochlear pathway in cats. J. Neurophysiol. 74:598-615, $1995 \mathrm{~b}$.

RAJAN R. Stability of efferent-mediated protection against acoustic overexposure with long maintenance under barbiturate anaesthesia. Audiol. Neurootol. 1:339-358, 1996.

RAJAN R. Centrifugal pathways protect hearing sensitivity at the cochlea in noisy environments that exacerbate the damage induced by loud sound. J. Neurosci. 20:6684-6693, 2000.

RAJAN R. Unilateral hearing losses alter loud sound-induced temporary threshold shifts and efferent effects in the normalhearing ear. J. Neurophysiol. 85:1257-1269, 2001a.

RAJAN R. Noise priming and the effects of different cochlear centrifugal pathways on loud-sound-induced hearing loss. J. Neurophysiol. 86:1277-1288, 2001b.

Rajan R. Cochlear outer-hair-cell efferents and complex-sound-induced hearing loss: protective and opposing effects. J. Neurophysiol. 86:3073-3076, 2001c.

Rajan R, Johnstone BM. Crossed cochlear influences on monaural temporary threshold shifts. Hear. Res. 9:279-294, 1983.

RAJAN R, JOHNSTONE BM. Electrical stimulation of cochlear efferents at the round window reduces auditory desensitization in guinea pigs. I. Dependence on electrical stimulation parameters. Hear. Res. 36:53-74, 1988a.

Rajan R, Johnstone BM. Electrical stimulation of cochlear efferents at the round window reduces auditory desensitization in guinea pigs. II. Dependence on level of temporary threshold shifts. Hear. Res. 36:75-88, 1988b.

Rajan R, Johnstone BM. Binaural acoustic stimulation exercises protective effects at the cochlea that mimic the effects of electrical stimulation of an auditory efferent pathway. Brain Res. 459:241-255, 1988c.

Raphael Y, Lenoir M, Wroblewski R, Pujol R. The sensory epithelium and its innervation in the mole rat cochlea. J. Comp. Neurol. 314:367-382, 1991.

Reiman AJ, Terhune JM. The maximum range of vocal communication in air between a harbor seal (Phoca vitulina) pup and its mother. Mar. Mamm. Sci. 9:182-189, 1993.

Reiter ER, Liberman MC. Efferent-mediated protection from acoustic overexposure: relation to slow effects of olivocochlear stimulation. J. Neurophysiol. 107:147-159, 1995. 
Roberts BL, Meredith GE. The efferent innervation of the ear: variations on an enigma. In: Webster DB, Fay RR, Poppen AN (Eds.) The Evolutionary Biology of Hearing Springer-Verlag, New York, pp 185-210, 1977.

Robertson D, Harvey AR, Cole KS. Postnatal development of the efferent innervation of the rat cochlea. Dev. Brain Res. 47:197207, 1989.

Rosen M, Lemon RE. The vocal behavior of spring peepers, Hyla crucifer. Copeia 1974:940-950, 1974.

Römer H, Bailey W, Dadour I. Insect hearing in the field. III. Masking by noise. J. Comp. Physiol. A 164:609-620, 1989.

Ryan MJ, Brenowitz EA. The role of body size, phylogeny, and ambient noise in the evolution of bird song. Am. Nat. 126:787$100,1985$.

SABY JS, ThORPE HA. Ultrasonic ambient noise in tropical jungles. J. Acoust. Soc. Am. 18:271-273, 1946.

Sano T, Widmalm S-E, Westesson P-L, Yamaga T, Yamamoto M, Takahashi K, Michi K-I, Okano T. Acoustic characteristics of sounds from temporomandibular joints with and without effusion: an MRI study. J. Oral Rehabil. 29:161-166, 2002.

SAto M, Henson MM, SMith DW. Normal synaptic morphology of outer hair cells in the organ of Corti of the Japanese macaque. Hear. Res. 108:46-54, 1997.

Sato M, Henson MM, Henson Jr OW, Smith DW. 3-Dimensional serial reconstruction of outer hair cells in the organ of Corti of the Japanese macaque. Hear. Res. 135:29-38, 1999.

SCHWARTZ JJ, WELls KD. An experimental study of acoustic interference between two species of neotropical treefrogs. Anim. Behav. 31:181-190, 1983.

Seyfarth RM, Cheney DL, Marler P. Vervet monkey alarm calls: semantic communication in a free-ranging primate. Anim. Behav. 28:1070-1094, 1980.

SIEGEL JH, KIM DO. Efferent neural control of cochlear mechanics? Olivocochlear bundle stimulation affects cochlear biomechanic non-linearity. Hear Res. 6:171-182, 1982.

Simmons DD, Mansdorf NB, Kim JH. Olivocochlear innervation of inner and outer hair cells during postnatal maturation: evidence for a waiting period. J. Comp. Neurol. 370:551-562, 1996.

SMITH DW. Effects of contralateral noise on absolute thresholds in non-human primates: Is "central masking" an efferent-mediated peripheral process? In: AR Palmer, A Rees, AQ Summerfield, and R Medis (eds) Psychophysical and Physiological Advances in Hearing. Whurr Publishers, London, p 26-33, 1998.

TAKeyama M, Kusakari J, Nishikawa N, Wada T. The effect of crossed olivo-cochlear bundle stimulation on acoustic trauma. Acta Otolaryngol. 112:205-209, 1992.

Thompson AM, Thompson GC. Light microscopic evidence of serotoninergic projections to olivocochlear neurons in the bush baby (Otolemur garnettii). Brain Res. 695:263-266, 1995.

Thompson GC, Thompson AM. Olivocochlear neurons in the squirrel monkey brainstem. J. Comp. Neurol. 254:246-258, 1986.
Tuttle MD, Ryan MJ. The role of synchronized calling, ambient light, and ambient noise, in anti-bat-predator behavior of a treefrog. Behav. Ecol. Sociobiol. 11:125-131, 1982.

WARD WD, SAnti PA, Duvall III AF, Turner CW. Total energy and critical intensity concepts in noise damage. Ann. Otol. 90:584590, 1981.

WARR WB, GUINAN Jr JJ. Efferent innervation of the organ of Corti. Brain Res. 173:152-155, 1979.

WARren III EH, Liberman MC. Effects of contralateral sound on auditory nerve responses. II. Dependence on stimulus variables. Hear. Res. 37:105-122, 1989.

WASER PM, WASER MS. Experimental studies for primate vocalization: specializations for long-distance propagation. Z. Tierpsychol. 43:239-263, 1977.

WASER PM, BROWN CH. Is there a "sound window" for primate communication? Behav. Ecol. Sociobiol. 15:73-76, 1984.

WASER PM, Brown CH. Habitat acoustics and primate communication. Am. J. Primatol. 10:135-154, 1986.

Weber PC, Parnes SM, Strominger NL. The canine olivocochlear bundle arises from several distinct subnuclei of the superior olivary complex. Otolaryngol. Head Neck Surg. 97:151-152, 1987.

Wemmer C, Scow K. Communication in the felidae with emphasis on scent marking and contact patterns. In: Sebeok TA (Eds.) How Animals Communicate. Indiana University Press, Bloomington, IN, pp 749-766, 1977.

WiEDERHOLD ML, KIANG NYS. Effects of electrical stimulation of the crossed olivocochlear bundle on single auditory-nerve fibers in the cat. J. Acoust. Soc. Am. 48:950-965, 1970.

Winslow RL, SACHS MB. Effect of electrical stimulation of the crossed olivocochlear bundle on auditory nerve response to tones in noise. J. Neurophysiol. 57:1002-1021, 1987.

WinsLOW RL, SACHS MB. Single tone intensity discrimination based on auditory-nerve responses in backgrounds of quiet, noise, and with stimulation of the crossed olivocochlear bundle. Hear. Res. 35:165-190, 1988.

Yamasoba T, Dolan DF. The medial cochlear efferent system does not appear to contribute to the development of acquired resistance to acoustic trauma. Hear. Res. 120:143-151, 1998.

Yoshida N, Liberman MC. Sound conditioning reduces noise-induced permanent threshold shift in mice. Hear. Res. 148:213219, 2000.

Yoshida N, Kristiansen A, Liberman MC. Heat stress and protection from permanent acoustic injury in mice. J. Neurosci. 19:1011610124, 1999.

Zakrisson JE, Borg E. Stapedius reflex and auditory fatigue. Audiology 13:231-235, 1974.

Zheng XY, Henderson D, Hu B, Ding DL, McFadden SL. The influence of the cochlear efferent system on chronic acoustic trauma. Hear. Res. 107:147-159, 1997.

Zheng XY, McFadden SL, Ding DL, Henderson D. Cochlear deefferentation and impulse noise-induced acoustic trauma in the chinchilla. Hear. Res. 144:187-195, 2000. 